\title{
Firm Bosses or Helpful Neighbours? The Ambiguity and Co- construction of MNE Regional Management Mandates
}

\author{
Eva A. Alfoldi, University of Bradford \\ Sara L. McGaughey, Griffith University \\ L. Jeremy Clegg, University of Leeds
}

Eva A. Alfoldi

Faculty of Management and Law, Emm Lane, University of Bradford, BD9 4JL, UK Tel.: +44 1274235313 * Fax: +44 1274234405 * Email: E.A.Alfoldi@bradford.ac.uk

\section{Sara L. McGaughey}

Griffith Business School, Griffith University, Nathan campus, Griffith University, 170 Kessels Road QLD 4111, Australia

Tel.: +61 37354889 * Fax: +61 37355111 * Email: S.Mcgaughey@griffith.edu.au

\section{Jeremy Clegg}

Cromer Terrace, Leeds University Business School, University of Leeds, LS2 9JT, UK Tel.: +44 1133434512 *Fax: +44 1132334465 * Email: L.J.Clegg@lubs.leeds.ac.uk 


\section{Firm Bosses or Helpful Neighbours? The Ambiguity and Co- construction of MNE Regional Management Mandates}

\section{ABSTRACT}

As multinational enterprises (MNEs) increasingly disaggregate and disperse corporate headquarters (CHQ) activities, the allocation of regional management mandates (RMMs) to local operating subsidiaries is becoming more common. RMMs explicitly break with the traditional assumption of a clear separation between centralised and local decision-making. Yet we know little of how RMMs are enacted by the units involved, or how they evolve over time. Based on a case study of Unilever, we find that RMMs are inherently ambiguous, and identify circumstances under which ambiguity manifests and triggers cycles of sensemaking and sensegiving about the meaning of the mandate. These cycles result in the co-construction of the mandate by multiple units, with changes in RMM scope and governance over time. We also find that sensemaking and sensegiving are most intense among boundary-spanning middle managers. Our work challenges prevailing assumptions that mandates are largely unambiguous when assigned and are unilateral or dyadic accomplishments; demonstrates the importance of sub-unit level analysis in MNEs; and highlights the potential of structuration theory to enrich our understanding of sensemaking and sensegiving in organisations.

\section{KEYWORDS}

Distributed HQ activities; Regional Management Mandates; Ambiguity; Co-construction; Sensemaking; Sensegiving; Structuration; Subsidiary mandates 


\section{INTRODUCTION}

Recent years have seen a resurgence of interest in critically examining the role of corporate headquarters, or CHQ (e.g. Ciabuschi et al., 2012; Egelhoff, 2010; Menz et al., 2015; Nell and Ambos, 2013). CHQ activities are progressively unbound from a single unit and performed at various levels and locations within the multinational enterprise (MNE). MNEs are, for example, disaggregating and dispersing core parts of CHQ activities (e.g. Baaij et al., 2015; Baaij and Slangen, 2013; Birkinshaw et al., 2006); establishing regional headquarters (e.g. Chakravarty et al., 2017; Nell et al., 2011) or intermediate parents (Goold and Campbell, 2002); and assigning regional management mandates or creating similar 'virtual' setups (e.g. Alfoldi et al., 2012; Baaij and Slangen, 2013; Menz et al., 2015; Piekkari et al., 2010). As Menz and colleagues (2015, p.668) observe, however, there is a continuing need to 'better understand how the CHQ deals with a complex portfolio of heterogeneous business and international units [...] considering several organizational layers.'

In this paper, we examine how distributed HQ activities are enacted (i.e. interpreted and 'put into practice') by local operating subsidiaries which are mandated to oversee and manage subsidiaries in other countries. MNE subsidiaries that are assigned such regional management mandates or RMMs (Alfoldi, Clegg and McGaughey, 2012) are often local implementers focused on primary value chain activities (such as sales and marketing) in their local market (see Gupta and Govindarajan, 1991). Empirical evidence of widespread and growing use of RMMs is accumulating (e.g. Chakravarty et al., 2017; Schotter et al., this issue). However, unlike dedicated administrative regional headquarters (RHQs), subsidiaries with RMMs are required to perform headquarter-like activities in addition to their local implementer roles. We argue that this is a crucial distinction. The use of RMMs explicitly breaks with the traditional assumption of 'clear separation between centralised decision- 
making (the role of the corporate HQ and the RHQ) and local decision-making (the role of the subsidiary)' (Nell et al., 2011, p.87). When embodied in a single unit, these two roles create tensions and are potentially incommensurate.

Our early study of an RMM assigned to the Hungarian subsidiary of Unilever - one of the world's biggest fast-moving consumer goods (FMCG) manufacturers - identified significant potential advantages of RMMs from the corporate HQ perspective (Alfoldi et al., 2012). We also found heightened challenges of control and coordination for the mandated subsidiary, attributable in part to the absence of a clear separation in the decision-making roles described by Nell et al (2011). Nonetheless, our early study fell short of exploring what this meant for the implementation of the RMM. If we are to fully appreciate how RMMs may contribute to the effective management of complex MNEs and realise their potential benefits, we need to understand their nature and dynamics - in particular, how they are interpreted and put into practice at the local level.

In this article, we explore two fundamental research questions: (1) How are headquarters-assigned regional management mandates enacted by the units involved within the MNE? and (2) How do regional management mandates evolve over time? We address these questions through a rich qualitative case study set in Unilever, where we trace the evolution of the RMM first assigned to the Hungarian subsidiary in 1997 through to 2007, using both historical and real-time data. In so doing, we contribute to multiple organisational literatures.

First is the literature on dispersed and disaggregated headquarters activities in MNEs. Drawing on our data analysis, we present a conceptual framework - underpinned by a set of novel assumptions and arguments - that depicts the process by which RMMs are enacted and evolve. Our findings and theorisation challenge two dominant assumptions. In international strategic management, a prevailing assumption is that mandates and RHQ roles are 
unambiguous when assigned (see Rugman and Verbeke, 2001). In contrast, central to our framework is the inherent ambiguity of RMMs. We identify circumstances in which ambiguity may sufficiently manifest, such that it triggers iterative cycles of sensemaking and sensegiving about the meaning of the mandate. Sensemaking is the process through which individuals and organisations give meaning to complex, novel, ambiguous or confusing issues/events, and develop active responses to them (see Brown et al., 2015; Maitlis and Christianson, 2014; Mills et al., 2010; Weick, 1995). Meanwhile, sensegiving is the process of attempting to influence the sensemaking and meaning construction of other people (Gioia and Chittipeddi, 1991). We show how these cycles of sensemaking and sensegiving lead to changes in the scope and governance of the RMM.

Another assumption found in prior studies is that the assignment and dispersion of HQ activities or subsidiary mandates is either a unilateral accomplishment (i.e. assigned unambiguously by HQ, or initiated by the subsidiary) or a dyadic process of negotiation (i.e. shaped in interaction between HQ and the mandated unit). In contrast, we found that multiple units (subsidiaries and CHQ) are involved in sensemaking and sensegiving about the RMM. That is, the RMM is co-constructed over time by multiple units and across multiple levels within the MNE. Further, our work reveals that during this mandate co-construction process, the most intense sensemaking and sensegiving occurs at the middle management levels. By studying these levels, we explicitly respond to calls to consider the sub-unit level of analysis (Geppert et al., 2016; Menz et al., 2015).

Second, we make a contribution to the literatures on sensemaking and sensegiving by augmenting these lenses with sensitising concepts from structuration theory (Giddens, 1979, 1984, 1991) to enrich our analysis. Together, these perspectives helped us to better understand the co-construction of the RMM. Although structuration perspectives are increasingly applied in management (e.g. Jarzabkowski, 2008; Sillince et al., 2012) and international management 
(Dutta et al., 2016; Tempel and Walgenbach, 2007), we believe structuration theory complements sensemaking and sensegiving in ways that have remained largely unexplored especially in relation to advancing our understanding of power and influence in organisations. Our study points to this potential of structuration theory, thus making a more general contribution to management and organisation studies.

In the next section, we provide a brief overview of the literature on distributed HQ activities in the MNE, focusing on regional management mandates. We then describe our research method and provide case study background. With a view to making our theorising from this complex case more readily accessible to readers, we then present our conceptual framework and use it to structure our findings. We conclude with a discussion of our findings, and reflections on our main contributions and suggestions for future research.

\section{DISTRIBUTED HEADQUARTERS ACTIVITIES AND REGIONAL MANAGEMENT MANDATES}

MNE configurations that involve distributed HQ activities are frequently necessitated by the growing size, complexity and international reach of modern MNEs. Such MNEs often battle with simultaneous pressures for integration and responsiveness, as well as pressures for ever greater cost efficiency. The most common way in which HQ activities are dispersed in MNEs is the establishment of regional headquarters (RHQs). A RHQ is 'an organisational unit concerned with and involved in the integration and coordination of activities that provide the link between the region and the HQ’ (Nell et al., 2011, p.91). Although RHQ research has a long history, much of the extant literature is limited to descriptive or managerial perspectives (Preece et al., 2013). Specifically, the literature on alternatives to the 'traditional' administratively oriented RHQ is still scarce - despite evidence that MNEs use a variety of complex regional management mechanisms (see Alfoldi et al., 2012; Chakravarty et al., 2017; 
Conroy and Collings, 2016; Goold and Campbell, 2002; Piekkari et al., 2010; Schotter et al., this issue).

Our focus in this paper is the phenomenon of MNE corporate headquarters delegating certain HQ activities to local subsidiaries instead of dedicated RHQs. The most detailed conceptualisation of local subsidiaries with regional roles was developed in Alfoldi et al. (2012), from where we borrow the term 'regional management mandate' (RMM).

Subsidiaries with RMMs are required to perform HQ-like activities in addition to their local implementer roles. They stand in contrast to dedicated RHQs, which are predominantly focused on a region rather than a particular local market, even if they perform operational tasks such as managing sales or R\&D (see Preece et al., 2013).

The delegation of regional management responsibilities to operating subsidiaries is not new and has been noted under many names: 'local subsidiary mandate’ (Lasserre, 1996); ‘double-hatting’ (Schütte, 1997); 'partial regional charter' (Rugman et al., 2011) and 'patronage model' (Schuh, 2013). While most of these mentions have been confined to the theoretical level, recent empirical research suggests RMMs are increasingly used by MNEs (Chakravarty et al., 2017). Compared with establishing new administrative RHQs, the potential benefits of assigning RMMs to existing local subsidiaries include lower costs, the exploitation of local operating expertise on a regional level, increased local responsiveness and reduced monitoring burdens on CHQ (Alfoldi et al., 2012; Chakravarty et al., 2017). Yet, RMMs also have limitations. For example, Alfoldi et al. (2012) found that the establishment of a dedicated RHQ signifies the CHQ's attention and commitment to a region in a way that assigning RMMs to an established, locally-oriented unit cannot. Legitimacy of an RMM may well be questioned by the 'managed' subsidiaries who - until the RMM was granted - were peers (or 'neighbours') of the newly appointed 'managing' (or 'boss') subsidiary (Alfoldi et al., 2012). This represents a shift in the balance of inter-unit power. Similarly, in their study 
of RHQs, Nell et al (2011, p.97) found that the 'specific allocation of rights between corporate, regional and local levels, was in nearly all cases contested and constantly challenged'. Conceivably, such contestation would be even greater in RMMs, where the regional and local levels co-exist in a single subsidiary, necessitating ongoing negotiation and bargaining within and between the affected subsidiaries.

Yet, this conjecture stands somewhat in contrast to much of the existing literatures on both RMMs (Alfoldi et al., 2012; Chakravarty et al., 2017) and subsidiary mandates more generally (e.g. Birkinshaw, 1996; Birkinshaw and Hood, 1998; Galunic and Eisenhardt, 1996). Both literatures have tended to assume mandate creation and development to be a unilateral accomplishment: mandates are developed either by CHQ or through subsidiary initiatives, and then fulfilled by the subsidiary (albeit often in competition with other subsidiaries). More recent studies (Dörrenbächer and Gammelgaard, 2006, 2016) have suggested that there is two-way bargaining and negotiation between CHQ and the mandated subsidiary, pointing to a dyadic perspective on mandates. Complicating the picture, though, is inconsistency within single studies. For example, our own prior work (Alfoldi et al., 2012) explicitly characterises the MNE as a network of interdependent units, but then presents propositions that take a unilateral or dyadic (HQ-subsidiary) perspective (see, similarly, Dörrenbächer and Gammelgaard, 2016; Foss et al., 2012). Overall, our comprehension of how distributed HQ activities and mandates are enacted and evolve within the internal networks of MNEs is still fledgling.

\section{RESEARCH METHODS AND CASE BACKGROUND}

\section{Research Methods}

To address our research questions, we utilise an in-depth single case study (Stake, 1995; Yin, 2013) which investigates the enactment of a regional management mandate held by a 
local implementer subsidiary of Unilever in the Central and Eastern European (CEE) region. We compare and contrast the perspectives of members in three local implementer subsidiaries: Unilever Hungary (ULH), which holds the regional management mandate; and Unilever Croatia (ULC) and Unilever Slovenia (ULS), which are managed by ULH under the mandate. These units form one of Unilever’s ‘country clusters', i.e. a small regional grouping of subsidiaries (not to be confused with industrial clusters). Unilever Hungary, operating on a local market of about 10 million people, is mandated by CHQ to manage Unilever Croatia (market size about 4 million) and Unilever Slovenia (market size about 2 million) as 'satellite subsidiaries' and act as the cluster's link to CHQ. Such arrangements are especially common for subsidiaries located in countries with small markets (Li et al., 2010) that are relatively peripheral within the MNE, as in our case.

We adopt an exploratory approach with an epistemological stance of social constructionism. Multiple respondents' voices and interpretations are therefore at the heart of our data collection and analysis. Our methodological approach was closer to the inductive end of the spectrum, but may be best described as abductive (Dew, 2007; Peirce, 1960). That is, we started with broad theoretical sensitivity from the extant literature on distributed HQ functions in MNEs, but engaged in constant iteration between this and new theory and data over the life of the research. Our time frame was from 1997 to 2007, starting with the initial assignment of Unilever Hungary's RMM and finishing just as the subsidiary began to prepare for a significant reorganisation.

Primary data was gathered through interviews between 2005 and 2007, using 'snowball sampling' in the three units (ULH, ULC and ULS). We gathered data from thirty respondents: eighteen from Unilever Hungary, five from each of the two satellite subsidiaries, and two directors with CEE-level responsibilities, based at CHQ (both of whom had top management experience in ULH). Some granted us repeat interviews, taking the total number of interviews 
to thirty-five. We interviewed respondents at all except the very highest work level (WL6), which allowed us to build a nuanced picture of employees' involvement in the RMM at various operational levels. Key data about our interviewees is shown in Table I.

Insert Table I about here

Most of our data derived from a combination of respondents' retrospective and real-time accounts, collected through semi-structured interviews that were recorded and transcribed. We also used publicly available data sources such as company websites, market reports and managers’ social media profiles for basic fact-checking.

We mainly focus on the functional department known as trade marketing. Trade marketing is aimed at marketing Unilever's products towards customers such as grocery retailers, chemists and convenience stores (who sell the products on to the end consumer), as well as managing consumer promotions at the point of sale. As such, trade marketing may be seen as a 'bridge' between sales and marketing. A Croatian manager described trade marketing using a pithy metaphor: 'Sales wants results and turnover, and marketing wants image and market share. We are in between, and we have to dance to two types of music.' We also interviewed respondents in the marketing department, which emerged during data collection as contrasting with trade marketing in how the RMM was enacted at the sub-unit level. In addition, we sought the views of general directors (9), HR directors/managers (2) and factory managers (2).

Our analytic approach was designed not to test hypotheses, but to generate thick descriptions (Ryle, 1968) and to create the potential for - but no certainty of - an alternative 'way of seeing' (Wolcott, 1999) RMMs. During our analysis, we triangulated mainly across respondents: our phenomena and events of interest related mostly to managers’ lived experience, with few material traces. To this end, we kept and regularly discussed extensive 
analytical memos, mapping links between respondents, noting any inconsistencies between their accounts about the same event, and including possible reasons for these differences. We used the NVivo software to support an initially inductive analytic approach, as described in Gioia et al (2013). First, we identified first-order themes and patterns arising from our data the 'situationally, historically, and biographically mediated interpretations' (Van Maanen, 1979, p.540) used by respondents in their accounts of the nature and evolution of the RMM. Our second-order analysis moved to a more theoretical level in an abductive mode, where we examined our largely descriptive first-order findings for underlying explanatory dimensions. This involved a constant revisiting of the data and a search of diverse literatures to extend our theoretical sensitivity and grounding, challenging our emerging understandings. In particular, we sought to uncover and problematise our existing assumptions rather than simply reproduce established frameworks or understandings (Alvesson and Sandberg, 2013). Acknowledging the constructed nature of empirical material (Denzin and Lincoln, 2000), we do not see data as the 'ultimate arbiter' but as a 'partner for critical dialogue' in the interplay between theory and data (Alvesson and Sandberg, 2013, p.145).

During our early analyses, we found theoretical purchase in the literatures on sensemaking (Weick, 1995; Weick et al., 2005) and sensegiving (Gioia and Chittipeddi, 1991). As we carried on, we were able to discern a deeper structure in the data by drawing on concepts from structuration theory (Giddens, 1979, 1984, 1991). Giddens' notions of bounded knowledgeability of human agents, dialectic of control, ontological security, interpretive schemes, norms of justification, and allocative and authoritative resources proved useful sensitising devices for our analysis, as we explain later. Hence, our second-order mode of analysis sought to generate insights of potential relevance beyond our immediate study.

Our eventual data structure is shown in Figure 1. Sensemaking and sensegiving are second-order process concepts, linked to the first-order themes arising from our data through 
state concepts borrowed from structuration theory. For clarity, we elaborate each concept at the point where our related findings are presented.

Insert Figure 1 about here

Our study is not without limitations. For example, it would have benefited from more access to CHQ-level respondents and more subsidiaries, but was constrained by finite resources. The micro-level processes involved in sensemaking, sensegiving and structuration remain beyond our direct observation. Only a portion of our longitudinal research was 'realtime' as events unfolded, and we do not trace events prior to the assignment of the RMM to infer earlier sensemaking and sensegiving processes. Such limitations are inherent in the nature of our work, and they make awareness of our role as interpreters of our empirical material - as well as reflexivity about our own sensemaking and sensegiving - even more crucial.

\section{Case Background}

Unilever is one of the world's largest manufacturers of fast-moving consumer goods (FMCG), with an annual turnover of over $€ 52$ bn (Unilever, 2016). The company manages a highly diversified portfolio of branded products (foods, refreshments, home care and personal care), operating in an industry characterised by high pressure for local responsiveness (differing consumer tastes, especially in foods) and the increasing need for regional or global integration to leverage well-known brands worldwide. During our data collection, Unilever was moving away from its historical roots as a federative MNE focused on local responsiveness and subsidiary autonomy (see Andersson et al., 2007) towards a more integrated structure with increasingly centralised decision-making, akin to rivals such as Procter \& Gamble. In 2006, Unilever’s regional structure consisted of three triads, six regions and several country clusters (see Figure 2). Units at the cluster level were all operating units 
(some with RMMs), while units at the levels above were primarily focused on strategy and coordination (RHQs and CHQ).

Insert Figure 2 about here

Unilever's factories in the Central and Eastern European (CEE) region were nationalised following the Second World War, forcing the company to exit. From the 1970s, Unilever re-entered through licensing and exporting, largely managed by the Unilever Export unit in Bristol, UK. After 1990, as CEE countries began to open up, Unilever entered several markets sequentially, often 'piggybacking' on its existing ventures. It was through this piggybacking logic that Unilever Hungary (ULH), established in 1991, was assigned a regional management mandate in 1997 to take responsibility for the so-called South Central European (SCE) sub-region. SCE included Bulgaria, Albania and the former Yugoslav republics of Slovenia, Croatia, Bosnia-Herzegovina, Serbia-Montenegro and FYR Macedonia. These were countries that CHQ considered promising markets to enter, but too small to justify direct supervision. Out of these seven countries, Croatia and Bulgaria already had existing Unilever subsidiaries which were moved under ULH's supervision. In the other five countries, ULH was tasked with establishing local subsidiaries from scratch. However, in 1999 CHQ decided to reduce the scope of ULH's regional mandate from seven to just two countries (Croatia and Slovenia). The other five countries were moved under Unilever Romania's supervision, for reasons that we explain in our findings. When we approached the company, Unilever Hungary’s RMM related only to Unilever Croatia and Unilever Slovenia. This cluster of three subsidiaries provided a rich, complex case for us to investigate. 


\section{MANDATE AMBIGUITY AND CO-CONSTRUCTION OF REGIONAL MANAGEMENT MANDATES}

Our conceptual framework, derived from our data analysis, is shown in Figure 3. It presents our five core concepts - mandate ambiguity, mandate context, sensemaking, sensegiving and mandate co-construction - that were highlighted in our data structure (Figure 1). Essentially, our framework suggests that there is an inherent ambiguity in regional management mandates assigned by CHQ to local subsidiaries. This ambiguity may remain latent, but may also manifest - particularly in the context of a federative MNE (see Andersson et al., 2007) that is moving towards integration. Through threats to identity or to ontological security - a sense of order, of continuity in experience, and of one's place in the world (see Giddens, 1991) - mandate ambiguity triggers cycles of sensemaking and sensegiving between the units involved (including CHQ, the mandated subsidiary and the managed subsidiaries). These cycles of sensemaking and sensegiving, in turn, lead to ongoing changes in the scope and governance of the mandate, and thereby to the co-construction of the mandate over time.

\section{Insert Figure 3 about here}

We present our detailed analysis below, starting with the inherent ambiguity of the CHQ-assigned RMM. Our analysis is complemented by Tables II and III showing quotes that illustrate key themes from our data. To protect our respondents’ anonymity, we only note their functional department when it is necessary for the interpretation of a quote. Work levels are indicated for Hungarian respondents, but not for Croatian or Slovenian respondents, as the small size of their units means that some respondents may be identified by their work level.

\section{The Ambiguity of Regional Management Mandates}

Like many others, we regard ambiguity as an inevitable feature of organisational life (Alvesson, 2001; Alvesson and Sveningsson, 2011; Martin and Meyerson, 1988). Building on Alvesson and Sveningsson's definition of ambiguity as ‘uncertainty and incoherence that is 
more or less continual and that cannot be significantly reduced through more information' (2011, p.351), we define mandate ambiguity as the possibility that a mandate may be understood in terms of different meanings, of which it is not possible to determine 'the best one’. However, we also recognise that human agents' desire for ontological security (Giddens, 1984, 1991) drives them to try to manage ambiguity in such a way as to maintain a continuity of experience. Through choices between competing meanings, and justifying these choices to themselves and to others, agents seek to reduce the negative consequences of ambiguity. The degree of ambiguity depends on the circumstances surrounding the mandate. We posit that while some ambiguity is always present, it may remain latent or unnoticed, unless contextual aspects cause it to manifest.

Our analysis suggests that upon receiving a RMM for the South Central European (SCE) region in 1997, Unilever Hungary faced three circumstances that heightened mandate ambiguity. First, the mandate concerned the complex and unfamiliar task of establishing/managing fully-fledged operating units over an indefinite period - as opposed to 'hosting' a specific product or time-bound project. Second, responsibilities included in the RMM were defined by CHQ at an aggregate level, without detailed directives on what they contained. In the words of a Hungarian manager:

'[We] have only one responsibility, to meet the [financial] target set for the Unilever Hungary Group. How this is done is less of interest to [CHQ].'

Third, no written charter or document was created to officially record the responsibilities contained in the mandate. When asked if the RMM arrangement was formally recorded, ULH's former vice-chairman, an expatriate sent to Hungary by CHQ, responded:

'That is not the Unilever style. The decision is taken and then executed [...] Of course, there was a formal decision, but there was nothing written at all. That is a normal development process inside of Unilever.'

These conditions created considerable scope for different interpretations and uncertainty about the meaning and content of the mandate, and how it might be best put into practice. 
Nonetheless, by themselves, these conditions did not cause mandate ambiguity to manifest immediately. Looking at the subsidiary-level events on the timeline in Figure 4, it is notable that during the first three years of the RMM (1997-1999), ULH's board chose to manage the seven countries contained within SCE as a business unit separate from the company’s Hungarian operations - much like a miniature ‘international division’. As there was virtually no operational contact or overlap between the Hungarian side and the SCE side of ULH's business, the inherent ambiguity of the mandate caused few tensions or conflicts - and thus went largely unnoticed.

Insert Figure 4 about here

This situation changed considerably in 1999 when CHQ split the SCE cluster in two, leaving only the two most developed countries (Slovenia and Croatia) under Unilever Hungary's supervision, and moving the responsibility for the other five countries to Unilever Romania. This decision significantly reduced the geographic scope of ULH's regional mandate. Having been left with only two satellite subsidiaries, the ULH board made a pivotal decision to abolish the separate team that had been managing the SCE region. ULH endeavoured to bring its remaining 'charges' into its own operating structure, with a view to close functional integration between the three units. Our data shows that this was the point where mandate ambiguity began to manifest and led to multiple interpretations of the RMM's meaning, with no clear or obvious 'best' interpretation.

While we found that all respondents were aware of the basic objective of ULH's RMM (to manage the satellite units and act as an 'intermediate parent'), we found distinct differences in interpretations about how this objective ought to be fulfilled and by whom. Heterogeneity of interpretations by work level and functional department. As the quotes in Table II show, the meaning of the mandate - and indeed, ambiguity itself - was perceived differently by respondents at different work levels (WL1-WL5) within ULH. Directors at the 
highest work levels (WL4-WL5) had been assigned relatively formal strategic authority over the three countries. Unsurprisingly, they perceived little ambiguity about the mandate. They viewed regional roles as a fundamental part of their job and discussed these in very clear terms: accountability for the business results of ULC and ULS, inter-unit reporting lines and 'cascading' working methods received from CHQ down to the satellite units. In contrast, ULH managers at the lowest operational levels (WL1-WL2) were mainly evaluated based on their local performance (even though 'on paper' some of them were responsible for the other countries too). They noted a vague sense of connection to their Croatian and Slovenian colleagues and were willing to share materials, look after visiting colleagues or travel to the other countries if requested. However, their inter-unit contact was too limited and episodic for any strong sense of ambiguity to manifest. Overall, mandate ambiguity did not seem to be a major concern for our respondents at the top or bottom levels within Unilever Hungary.

Insert Table II about here

It was when we asked respondents at the middle management level (WL3) - i.e. those with boundary spanning roles - that we found a more complex picture. They not only had varying interpretations of the mandate, but also showed a heightened awareness of mandate ambiguity. Several of our WL3 respondents (regardless of the extent of their formal accountability) admitted that they were not sure (or had not been sure, at times) what specific activities their inter-unit responsibility entailed, as illustrated in Table II. This frequently proved a source of tension and conflict for them, both in terms of communication with colleagues and on a personal level.

We also found marked differences in mandate interpretation by functional department. In the marketing department, ULH managers constantly pushed for ever closer collaboration, harmonisation and coordination of plans across the countries. Meanwhile, in trade marketing, Hungarian managers had a more hands-off approach towards Croatian and Slovenian 
colleagues. This heterogeneity in interpretations not only affected inter-unit linkages on an everyday basis, but also led to different inter-unit reporting structures. At the time of data collection, ULH WL3 marketing managers were formally accountable for the two satellite units, which reported directly to them. Meanwhile, ULH trade marketing managers only had informal inter-unit links or 'dotted-line’ reporting.

These differences between the two departments are partly explained by greater pressures for regional integration in marketing (need to harmonise brand image, packaging and advertising) and greater pressures for local responsiveness in trade marketing (need to accommodate local trade structures and retailers). Nonetheless, a key feature of ambiguity is that even in the presence of clear rationales and sufficient information, it is not possible to tell clearly which of two competing meanings or solutions is superior. The marketing department's integrated approach, despite performing generally well, led to some failed product launches in Slovenia with long-term consequences. Meanwhile, although trade marketing's hands-off approach was widely considered the 'correct' one for that department, the low level of contact led to ULC and ULS falling behind in terms of trade marketing standards and innovations for extended periods.

Our analysis of heterogeneous interpretations at the sub-unit level reveals a highly complex picture. Nonetheless, we were able to discover some consistent themes from our data regarding ULH respondents’ views about two key aspects: the nature of their RMM-related responsibilities (primary versus secondary) and their orientation towards the other units (control versus support).

Primary versus secondary responsibility. As quotes in Table II illustrate, the RMM is viewed by some managers (in particular at higher work levels and/or in marketing) as a geographic extension of their primary responsibility. For these respondents, the RMM means that the tasks they have in Hungary (product and people management, planning, knowledge transfer, 
representation at higher levels, etc.) include Croatia and Slovenia on an everyday basis. They showed great concern and knowledgeability about the Croatian and Slovenian markets. In contrast, other respondents (especially at lower work levels and/or in trade marketing) viewed the mandate as a secondary responsibility on top of their primary responsibilities in Hungary. They were happy to answer queries from the other units and provide assistance on demand, but regarded this as being of secondary importance to their tasks in Hungary and subject to their time and goodwill. They appeared less knowledgeable and/or concerned about the two other markets.

Both of these contrasting views were generally accepted by Croatian and Slovenian respondents. Nonetheless, the ability of ULH managers to interpret the mandate either as a primary or a secondary responsibility underlines the contrast between RMMs and RHQs (whose regional role is, by definition, a primary responsibility for managers).

Control versus support orientation. When discussing the RMM, many ULH respondents emphasised aspects of control (e.g. monitoring operations in Croatia and Slovenia, authorising budgets, giving directives and ensuring compliance). Formal accountability was expected across country borders, suggesting that they perceive their role (or ULH’s role) largely as that of a 'boss'. Meanwhile, other ULH managers described the mandate (or their own part in it) mainly in terms of support: 'an understanding' that ULH managers will help Croatian and Slovenian colleagues where needed (e.g. by pooling resources, passing on information and best practices, solving problems) in an informal manner, but will not interfere unless asked. This suggests a perception of their role (or ULH's role) more akin to that of a 'good neighbour'. Table II provides illustrations of both types of orientation. A number of respondents showed a mixture of control/support orientations through their language and reasoning in our interviews, suggesting an underlying tension between their supportive intentions and their desire for control. The potential for such complex and, at times, 
incongruent orientations underlines the inherent ambiguity of the mandate. Again, our data suggests that it is the middle managers (WL3) who feel the impact of mandate ambiguity more keenly than others above or below them.

\section{Mandate Context: A Federative MNE with a View to Integration}

Unilever's historically decentralised federative structure meant that once CHQ allocated the RMM to ULH, it was largely left up to the local board to decide how to enact it. However, from 1999, Unilever’s corporate strategy became explicitly focused on achieving a greater degree of regional and global integration. Our data suggests that while Unilever's federative heritage created the conditions for high levels of latent mandate ambiguity, it was the subsequent shift towards integration and centralisation that caused this ambiguity to manifest. We found that the extent to which the ambiguity of ULH's RMM became apparent - and the ability of Unilever members to manage and reduce its negative impact - was influenced by several aspects of Unilever's changing context. These include organisational flux, organisational distance and connectedness, and subsidiary identity.

Organisational flux. Our study revealed considerable organisational flux (ongoing strategic, structural and/or operational change within an organisation) in Unilever. At the cluster level, sweeping strategic changes towards integration prompted frequent internal restructuring within Unilever Hungary, which exacerbated the ambiguity of the RMM. Regular restructuring cast doubt on who exactly was responsible for liaising with ULC/ULS managers and how often. It also hindered the establishment of enduring interpersonal ties between units. The quotes in Table II also illustrate the impact of a more general flux in personnel. This was particularly evident in the trade marketing department, where personnel changes on various sides were seen as a major barrier to working together. Organisational flux also led to increased uncertainty and unpredictability in the internal strategic and operating environment, thus heightening the degree of ambiguity experienced by managers. 
Organisational distance and connectedness. In addition to organisational flux, we found that the organisational distance between units also enabled the ambiguity of ULH's mandate to manifest. Our data reveals two types of organisational distance between the three subsidiaries: geographic (horizontal) and hierarchical (vertical) distance. Geographic distance refers to the physical distance between the units’ management offices: Budapest as the cluster centre, Zagreb (350km away) and Ljubljana (460km away). While these distances may seem small, the lack of co-location and face-to-face contact clearly hindered the development of shared understandings and integrated operations, as illustrated in Table II. Further, reliance on telephone and email made it easier for some ULH managers to 'forget about' their regional responsibilities and focus on the Hungarian market. Meanwhile, the hierarchical distance (institutionalised hierarchy) between the three units was at odds with CHQ’s and ULH’s originally stated intention to 'manage the three countries as one'. In ULC and ULS, even the top decision-maker (the country manager) occupied only a middle manager position (WL3). Meanwhile, in ULH the chair(wo)man and the functional/business unit directors occupied work levels WL5 and WL4, respectively. This meant that in practice, there was clearly one lead subsidiary and two satellite units, rather than a group of equals being managed jointly. This highlights the disparity between envisaged notions of the RMM and its actual implementation, heightening ambiguity.

We also found that Unilever Hungary had a much higher level of organisational connectedness (i.e. consistent ties and points of contact within the MNE) than either Unilever Croatia or Unilever Slovenia. In total, eight Hungarian respondents reported having expatriation experience outside the cluster (including at CHQ), while none of the Slovenian and Croatian managers that we interviewed had such experience. ULH members at middle and top levels benefited from higher-level connections. Even at lower work levels, we found examples of ULH managers attending European meetings (see Table II). In contrast, 
managers in ULC and ULS had much less access to these networks. These managers generally accepted the RMM structure as sensible and logical from Unilever's overall perspective, but highlighted some negative outcomes (e.g. their lack of access to European or global best practices). While there was no formal barrier stopping ULC and ULS from contacting other Unilever units, we found this depended on coming across ideas by chance or information filtered through ULH. Overall, their low organisational connectedness put ULC and ULS managers at an informational disadvantage, affecting their ability to deal with the ambiguity surrounding the mandate.

Subsidiary identity. Subsidiary identity provides answers to the question 'Who are we as a subsidiary?' (see Ashforth et al., 2008) and helps members to understand their 'place in the world' (Giddens, 1984) as distinct from, and in relation to, others (Albert and Whetten, 1985). We found that the three units in our case define themselves relative to each other; relative to rival companies; and relative to other Unilever units outside the cluster. As such, any changes in one unit's status or success may affect not only its own, but also other units' identities. In our interviews, ULH members noted their unit’s much larger size and longer history compared to ULC and ULS, in justification of their leadership role. Meanwhile, ULS and ULC members cited their units' smaller size, shorter operating history and limited human resources to justify their need to accept strategic direction and knowledge from ULH. All three subsidiaries considered themselves highly successful on their local market. In addition to size, history and financial performance, managers from all three countries noted examples of the collective competences residing in their own units. As shown in Table II, managers frequently linked their unit's accumulated competence to the level of development or sophistication of their local market, allowing each to feel advanced and even superior to other units in some regard. 
While the ambiguity of the RMM allowed members to develop multiple interpretations and justifications, the requirement to operate in an increasingly integrated manner challenged self-conceptions and notions of the 'best' way to operate. We found that these conditions generated threats to organisational members' identities and their sense of ontological security. These threats, in turn, prompted them to engage in more extensive sensemaking and sensegiving efforts about the RMM. Next, we examine these processes more closely.

\section{Responses to Mandate Ambiguity: Sensemaking}

Sensemaking has three key elements: information seeking, meaning construction and action (Thomas et al., 1993). Agents construct a sensemaking object by combining specific information or stimuli to create a meaningful and coherent 'picture'. Then, they use their consciously or unconsciously held mental models to develop meaningful explanations, make decisions and generate courses of action. Action forms an integral part of sensemaking, even when it means ‘doing nothing' or ‘carrying on as before’ (Weick, 1995; Weick et al., 2005). By monitoring the consequences of (in)action, agents continually refine their sensemaking objects and the mental models that they use to construct and enact meaning.

While sensemaking can be argued to take place both in individuals' minds and in the collective domain (Maitlis and Christianson, 2014), it is an inherently social process (Weick et al., 2005). Sensemaking is 'influenced by the real or imagined presence of others as well as by a person's sense of self' (Sandberg and Tsoukas, 2015, p.9). Therefore, any separation between individual and collective sensemaking is somewhat artificial. Empirically, although our raw data is captured through individual interviews, interviewees' responses are strongly influenced by their connections to (and within) Unilever. Their rich organisational descriptions, interpersonal connections and cross-references across multiple respondents allowed us to identify patterns of collective sensemaking and make inferences at the organisational level. We found that the first-order themes in our data (relating to sensemaking 
processes around mandate ambiguity) could be understood more deeply by drawing on sensitising concepts from structuration theory (Giddens, 1979, 1984, 1991).

Threats to identity and ontological security as sensemaking triggers. Sensemaking is deeply entwined with identity (Weick, 1995) and is frequently triggered by events or conflicts that threaten agents' individual or collective identity (see Dutton and Dukerich, 1991). Identity threats relating to the RMM are illustrated by this quote from a Hungarian manager:

'I think the Croatians somehow...intellectually loathed the fact that...these Hungarians were "sitting on a throne" above them and were telling them how to run the business. And the Slovenes even more, I think, because they see themselves as being above everybody - Hungarians, Croatians, anyone - well, they have a [very high] GDP, and they are right next to Italy and Austria...So they think, what the hell are we trying to explain to them about the business?'

More generally, ambiguous situations may also present a threat to sensemaking agents’ ontological security, i.e. the need for a sense of order and continuity in experience (see Giddens, 1991). We found two types of triggers for sensemaking about the RMM: acute (episodic) and chronic (ongoing). Acute triggers include shifts in the scope of ULH's mandate: first, adjusting from a purely local mandate to a regional mandate in 1997; and then the removal of five countries from the RMM in 1999 (see Figure 4). This latter event had a negative impact on ULH's identity as a successful and competent regional leader, as well as on ULC and ULS, whose business links with other former Yugoslav countries were suddenly severed. These changes necessitated the construction of new meanings about the mandate and how it should be put into practice. Other acute triggers included failed product launches, external jolts such as retailer demands and realisations of lagging behind, as illustrated in Table III. More generally, we found that sensemaking was necessitated by chronic triggers, including Unilever's progressive shift towards integration, centralisation and customer focus; as well as persistent conflicts arising from the ambiguity of ULH's mandate.

Insert Table III about here 
Interpretive schemes. During sensemaking, agents rely on interpretive schemes. These are 'shared, fundamental (though often implicit) assumptions about why events happen as they do and how people are to act in different situations’ (Bartunek, 1984, p.355; see also Giddens, 1984, p.29), that form the core of shared knowledge by which one's world is understandable. The interpretive schemes that managers use in their sensemaking are built on two key types of knowledge: empirical knowledge (what agents have experienced first-hand) and institutional knowledge (accepted frameworks and shared understandings that govern how things are done in the organisation - 'the Unilever way'). Examples of empirical knowledge include managers’ own experience of what works on their market (including trial-and-error); foreign expatriation or work experience in different functional departments; and exposure to higher levels within the company. Regarding institutional knowledge, ULH middle managers and above (WL3-WL5) receive a constant flow of working methodologies and planning templates from CHQ. This creates an ongoing institutional influence on the interpretive schemes that they use to make sense of the RMM. Managers' sensemaking about the mandate is also shaped by Unilever's corporate culture. The influence of institutional knowledge on the interpretive schemes used in sensemaking can be subtle, or even overridden by an agent's empirical knowledge.

Norms of justification to self. During sensemaking, agents deploy norms of justification, i.e. the institutionalised moral principles used to justify their interpretations and actions, and related sanctions (see Giddens, 1984). Our data suggests that Unilever members invoke such norms - consciously or unconsciously - to legitimise and justify their views about the RMM to themselves, including what they believe to be CHQ's reasons and expectations. Table III shows examples of norms of justification being deployed in sensemaking about mandate allocation (e.g. perceived reasons why CHQ awarded the mandate to ULH) and mandate enactment (e.g. focus and attention afforded to one market over another). 
Bounded knowledgeability of agents. Sensemaking agents are generally assumed to be competent and reflexive - however, it is important to recognise that their knowledgeability is bounded in many ways (Giddens, 1979, 1991). In our case, the knowledgeability of individuals as well as organisational units is bounded by several factors. These include organisational identity, access to information, conscious or unconscious filtering, biases, emotions, erroneous beliefs and unacknowledged conditions. The influence of bounded knowledgeability on RMM enactment is illustrated by the failed launch of basic variants of Domestos and Cif cleaning products in Slovenia in 2001. ULH managers relied on their empirical knowledge (the basic variants had sold well in Hungary) and their institutional knowledge (Unilever's global strategy was to harmonise products where possible), to justify launching the same variants in all three countries. ULH management enforced this plan, despite the protests of Slovenian management, who argued that Slovenian consumers would reject the basic variants and demand the more sophisticated variants that were available in neighbouring Italy and Austria. Arguably, ULH decision-makers had an erroneous belief that in the home care business, the Slovenian market was on par with the Hungarian market. They consciously or unconsciously filtered out information that was at odds with this belief (such as evidence that Unilever's rivals were already selling more sophisticated product variants in Slovenia at the time). The basic variants indeed failed to meet the expectations of Slovenian consumers, resulting in an irreversible loss of sales and market share as an unintended consequence (see Giddens, 1984). Nonetheless, bounded knowledgeability works both ways ULH's decision to launch the standardised versions may have been prompted by directives or expectations from CHQ, of which Slovenian managers (given their limited organisational connectedness) may not have been aware. ULH’s self-identity as a successful, pioneering subsidiary and capable cluster leader, combined with a perception of the Hungarian market as being highly developed, may have also influenced decision-makers’ sensemaking. 


\section{Responses to Mandate Ambiguity: Sensegiving}

Sensegiving is about 'making sense for others' in an attempt to influence their thinking (Gioia and Chittipeddi, 1991, p.442-443) and persuade them to accept the sensegiver's meanings. As such, it is closely connected to sensemaking, and may be conceptualised as a possible action arising from agents’ meaning construction (i.e. an effort to transfer that meaning to others). In our case, sensegiving plays an integral role in the three units' collective sensemaking cycles about the RMM. As with sensemaking, we draw on sensitising concepts from structuration theory. These include allocative and authoritative resource structures, referring to different types of media through which power may be exercised (Giddens, 1984, p.16), and the deployment of norms of justification to legitimise meanings to others - not only in terms of principles, but also in communication strategies.

Influence through mobilising allocative resources. Allocative resources refer to the ability to command objects, goods or material phenomena (Giddens, 1984, p.33; see also Jarzabkowski, 2008). They allow an individual or an organisation to access and deploy 'things' like money, physical assets, technologies of production and infrastructures. By mobilising its allocative resources, an MNE unit can influence the understandings and behaviours of members in other units, even without formal authority. ULH has considerably higher budgets to spend on training, market research, software and systems than ULC and ULS, which operate on much smaller markets, with proportionately smaller income generation capabilities. Quite apart from any hierarchical distance between the three units, ULH has far more financial resources that can be allocated to the accumulation of new knowledge and expertise on the Hungarian market (e.g. buying-in market research or training from external consultants). This knowledge and expertise, in turn, can be used to convince and give sense to the smaller units under the RMM. In contrast, ULC and ULS lack the budget to employ enough people to match ULH's higher-level competences - in the words of a Croatian manager: 'If we only have two guys for 
producing all these [promotions], then nobody is doing strategic thinking.' This gives them less power to influence managers in ULH. In addition, ULH commands more developed infrastructure and systems for training and HRM than its counterparts in Slovenia and Croatia. As a result, decisions about training and management development in the smaller countries are significantly influenced by Unilever Hungary. In summary, its superior allocative resources place ULH in a dominant position to shape how the content of the mandate is interpreted.

Influence through mobilising authoritative resources. Authoritative resources refer to the ability to command people (Giddens, 1984, p.33; see also Jarzabkowski, 2008). They include resources such as formal (assigned) authority and hierarchical position that gives legitimacy to command, and informal authority through social contacts, information access or recognised expertise. Authoritative resources can be mobilised to influence the understandings and behaviours of others, often in concert with allocative resources (and sometimes compensating for a lack of allocative resources). In our case, ULH has formal authority over ULS and ULC - assigned by CHQ, who has the ultimate authority. Managers in ULH tend to have higher hierarchical positions (work levels) than their Croatian and Slovenian colleagues in broadly equivalent job roles. But while formal authority is an important authoritative resource, it does not guarantee power over others. A WL3 manager in Hungary reported that formally, they had full authority over Croatian and Slovenian plans. However, when conflicts arose over those plans, the manager was asked by higher-level directors to 'treat the Croatians sensitively' and not interfere. At the same time, many ULH managers enjoyed a level of informal influence over their Croatian and Slovenian colleagues’ sensemaking - sometimes well beyond their level of formal authority - due to their social contacts, recognised expertise or performance record (particularly in the trade marketing department). 
Finally, even though ULH dominates the cluster through both formal and informal authoritative resources, ULS and ULC also command a degree of influence through their local autonomy and self-determination capabilities, as illustrated in Table III. The power to push back and say 'no’ reflects the 'dialectic of control' (Giddens, 1984, p.16) - that is, ways in which subordinates can influence their superiors. Unilever Slovenia, in particular, has enhanced bargaining power to stand up to ULH thanks to the high GDP/capita and demanding nature of Slovenian consumers. As such, ULH managers have to work harder to convince ULS managers, while Croatian managers operating on a less developed market are generally (although not always) more receptive to sensegiving efforts from ULH managers. Overall, we found that authoritative resources are not solely held by ULH, and this shapes how the RMM is put into practice.

Norms of justification for sensegiving. Akin to sensemaking, sensegiving involves the deployment of norms of justification (Giddens, 1984). Whereas during sensemaking norms of justification may be invoked only in a latent or unconscious manner ('justification to self'), in sensegiving these norms must be articulated to legitimise meanings ('justification to others'). Hence, norms of justification used during sensegiving relate not only to the principles invoked to justify meanings or actions, but also to how these principles are communicated. We found that ULH managers engaged in sensegiving draw explicitly on justification principles such as formal expectations by $\mathrm{CHQ}$, the necessity of business risk minimisation, and a belief that Hungarian working methods are 'best practices' and should therefore be implemented in Croatia and Slovenia too (see Table III). Our data also suggests that communication strategies which demonstrate trust and tact are vital for sensegiving. We talked to Hungarian managers who had been expatriated to Croatia and Slovenia for varying periods, in earlier days as country managers (cf. control orientation) and later on as expert coaches (cf. support orientation). While we could not directly observe instances of their 
sensegiving to Croatian and Slovenian colleagues, we noted that they consistently phrased their explanations to us in supportive rather than controlling terms, emphasising notions of equality and respect. Arguably, this suggests a desire to be seen as good neighbours consistent with a culture of autonomous units in a federated network who are increasingly required to work together. For example, to cultivate an atmosphere of trust necessary for effective sensegiving, Hungarian managers had to learn to avoid the term 'Balkan' with its connotations of low levels of development, and adopt specific ways of addressing and showing respect to colleagues from the other countries, as Table III shows.

In summary, our analysis suggests that sensemaking and sensegiving are processes triggered by threats to agents' identities and ontological security, and involve organisational members deploying interpretive schemes, norms of justification and allocative and authoritative resources, under conditions of bounded knowledgeability. Next, we draw these concepts together to examine how cycles of sensemaking and sensegiving give rise to the coconstruction of regional management mandates over time.

\section{Mandate Co-Construction through Sensemaking and Sensegiving}

Mandate co-construction is a complex process that is not directly observable. Nonetheless, our rich longitudinal data allows us to trace key formal and informal changes in both the scope and the governance of ULH's RMM to illustrate co-construction in action.

Changes in mandate scope. By 'scope', we refer to the geographic domain of a regional management mandate. As Figure 4 shows, the RMM allocated to Unilever Hungary in 1997 underwent formal changes in geographic scope in 1999 and 2006. In 1999, ULH’s regional mandate was reduced from seven countries (which were making an attractive contribution to ULH's overall profits) to just two countries (Croatia and Slovenia). This was a result of sensemaking and sensegiving efforts by several organisational units, including CHQ. Expatriate top managers in Unilever Romania used their influence and connections to 
persuade CHQ that the responsibility for less developed SCE countries should be transferred to their unit. For this, they drew on norms of justification such as Unilever Romania's slack human and financial resources and similar levels of market development. These arguments were accepted by CHQ, who then gave these reasons to top management in Hungary to legitimate the formal reduction in the scope of ULH’s regional mandate. In our interviews, many ULH respondents repeated these arguments as reasonable justifications for the SCE split. Nonetheless, those Hungarian respondents who had been the most closely involved with the SCE region also voiced some criticisms, as the following quote from the SCE regional director (WL4) shows:

'Bucharest was full of experienced expats who, for various reasons, could not perform in Romania according to expectations - so it was logical, from Unilever's macro-economic resource management point of view, to move this "burden" over to Bucharest [...] To be honest, I was against this at the time, saying "why should a business managed using such miniature resources be split in two?" - but there are many aspects within a business.'

Despite talking to several ULH directors who were directly involved in this event, we uncovered little evidence of any significant resistance by ULH. This may be because at the time, the chairman and many ULH board members were foreign expatriates, and perhaps expecting to move on in the future. As such, they were less likely to perceive the reduction in the RMM's scope as a threat to their professional or national identity. In contrast, the Hungarian directors and managers involved, who had relatively little authority to challenge this decision, regarded the move as a 'downgrade' that ignored the accumulated capabilities and regional expertise of ULH (see Ambos et al., 2009 for a similar finding). Croatian and Slovenian managers perceived the organisational separation from units in other former Yugoslav countries as 'difficult' and 'very, very painful', and opined that existing cultural and business links should have trumped arguments about slack resources and market development. Nonetheless, at the time of the split, they lacked sufficient information to understand the decision, or the clout to influence it: 
'I...simply cannot see what was the real reason behind that, because I was also fresh in the company at that time and I was not so much exposed that I could shape the argument, discussion.'

While CHQ's decision to split up the SCE region may have been motivated by valid strategic rationales at the MNE level, it had unintended negative consequences at the operating level. After 1999, it became harder for ULS and ULC to negotiate with some of their biggest retail customers (who wanted SCE-level contracts), and sales in Bosnia stagnated. Being relatively small and peripheral, the subsidiaries' concerns did not attract immediate attention from CHQ. Nonetheless, by mid-2006, ULH and ULC managed to jointly persuade CHQ to partially reverse its earlier decision, and the responsibility for Unilever Bosnia was formally returned from Romania to Hungary. Using authoritative resources (e.g. Unilever Croatia's strong business contacts in Bosnia and good relations with the newly re-established CEE team at CHQ), the sensegiving efforts directed upwards paid off, resulting in an increased scope for ULH's RMM again:

'We started discussions about the changes of the setup, and we were supported by the CEE group president, who decided that from this year on [...] Bosnia is coming back to us; which makes a lot of sense for Unilever because of organisational efficiency [...] There is clear and obvious synergy between Croatia and Bosnia.' (Croatian manager)

Changes in mandate governance. During our case period, we also observed numerous changes in the RMM's governance, by which we mean the manner of governing the units involved in the mandate. These included formal changes in the RMM's governance structure, as well as informal changes in ULH's approach to governance. These changes are presented in chronological order to correspond with the timeline in Figure 4.

The reduction of the scope of Unilever Hungary’s original RMM in 1999 triggered a move from the 'separate division' structure previously applied to the SCE region, to the formal integration of ULC and ULS into ULH's own functional structure. Slovenia and Croatia suddenly appeared on the radar of managers who had previously only focused on Hungary, and the inherent ambiguity of the mandate began to manifest. This triggered 
sensemaking efforts about what integration meant in terms of expectations and responsibilities. As a Croatian manager explains:

'[From 1999] suddenly we have everything together - so of course, it takes some time...to fix it and just to think that there are some other things now and some other countries to think about.'

During the initial integration period (1999-2000), the country managers in both Slovenia and Croatia were Hungarian expatriates from Budapest, allowing ULH a high degree of control and supervision. However, managers in functional departments were initially unsure about the 'best way' to approach integration. In marketing (dominated by integration pressures), managers viewed the RMM as an extension of their primary responsibilities and demonstrated an orientation towards control. In trade marketing (dominated by responsiveness pressures), managers viewed the RMM as a secondary responsibility and showed an orientation towards support (although with overtones of control at times). Nonetheless, during this early integration period, contact between the units in both departments was governed by relatively ad-hoc monitoring, planning and responses to specific needs.

By 2001, the two functional departments had developed contrasting formal structures. In trade marketing, in keeping with Hungarian managers’ secondary responsibility/supportoriented view of the mandate, Croatian and Slovenian managers continued to report to their local country manager and had no functional reporting lines to Hungary. Meanwhile in marketing, the increasing amount of cross-border contact and Hungarian managers’ primary responsibility/control-oriented view led to Croatian marketers reporting directly to Hungary (with the Slovenian marketing department reporting indirectly via Croatia). The accounts of several respondents indicate that this early phase of integration (1999-2001) was a turbulent time that shaped managers' interpretations and actions through the tensions and conflicts that arose (e.g. failed product launches). Triggered by these tensions and inter-unit conflicts - and arising in part from the sensegiving efforts of Slovenian and Croatian managers - ULH 
marketing managers began to realise that enforced compliance would not work. This precipitated a gradual shift in their governance approach, independently of the governance structure in place. Over time, cycles of joint sensemaking and sensegiving fed into the coconstruction of the mandate - illustrated powerfully in this account given by a Hungarian middle manager (also supported by our interviews with Slovenian managers):

'It was declared [by CHQ] that they [ULS and ULC] belong to us absolutely. [...] In the beginning, this is how we understood them belonging to us: "If we introduce [a product], you are going to introduce it, too". This is how we defined belonging together. [...] In vain did they say: "We are different, we are not Hungary!" and so on, we said: "Okay, of course, but go and introduce it anyway!" [...] After some time, as they came to visit more, we got to know each other, we talked more, we realised this was not going to work like that. [...] I could see more and more that our managers were required to go out there and liaise with the marketing teams. Marketing approached the countries with a different outlook, and that led to trade marketing doing different things as well. [...] This was a continuously developing thing, so it was far from perfect...'

In addition to these informal changes in the units' views of the meaning of the RMM, we also uncovered evidence of formal changes in mandate governance over time. During the period 2003-2004, responsibilities and reporting lines between the three units were revised in a number of ways by the ULH board, with the aim of further increasing functional integration. To this end, Slovenian marketers were now required to report directly to Hungary (rather than via Croatia, as before), removing a level of separation between them and their bosses (WL3 managers) in Hungary. Meanwhile, Hungarian marketers at the WL2 level (who previously had no formal link to Slovenia or Croatia) became formally accountable for Unilever's business results in the two smaller countries as well. This formal change in mandate governance was justified by the increasing centralisation of marketing directives across Unilever, and the need for all marketers responsible for a specific brand within the cluster to work together more closely. Nonetheless, since WL2 marketers in Hungary were on the same work level as their Croatian and Slovenian counterparts (who were already formally reporting to Hungarian WL3 managers), no new reporting lines were created to accompany this stated 'formal accountability'. Our respondents' accounts suggest that this situation of heightened ambiguity led to persistent confusion and uncertainty stretching over months or even years: 
'It was not clear [...] are the [Hungarian] brand managers responsible also for Slovenia or not? What is their responsibility, to what level? [...] We worked a lot on it, we agreed on the framework and still it didn't work. And then, you know, we repeated the whole story.' (Slovenian manager)

'We were basically messing around with it for 5-7 years, because nobody was able to say "let's do it like this, or like that, and who's responsible for what" [...] Okay, it worked relatively well, but this depended mainly on the people. So the organisational structure didn't really help the flow and the unambiguous, clear operation of the company.' (Hungarian manager, WL3)

Around the same time, Unilever CHQ was orchestrating a strategic shift in the management of its customer-facing functions (sales and trade marketing), and decided to set up a European sales directorate. For ULH trade marketing managers, this led to increased monitoring from above, as well as expectations that central directives would be fully implemented in every unit. As a result, ULH trade marketing managers came under growing pressure to shift from their support-oriented approach towards a more control-oriented approach. At the same time, they needed to respect the high degree of local responsiveness required in sales and trade marketing. Accordingly, ULH introduced ‘dotted-line’ (informal) reporting lines from Croatia and Slovenia to the Hungarian sales and trade marketing director (WL4). However, not only was this a much looser form of reporting than the formal 'straightline' reporting found in marketing, but our interviewees' responses varied as to whether these dotted reporting lines even existed or not. Others worked outside the structures: for example, one manager began to send minutes of meetings to the ULH chairman (WL5) who had ultimate responsibility for the cluster, thereby attempting to influence the behaviour of ULS and ULC indirectly.

Overall, these formal and informal changes in the scope and the governance of Unilever Hungary's RMM signify that the RMM is co-constructed by the units (and individuals) involved through ongoing cycles of sensemaking and sensegiving, rather than being defined or imposed by CHQ or Unilever Hungary. 


\section{DISCUSSION}

In this paper, we have sought to understand how distributed HQ activities are undertaken by local operating subsidiaries mandated to manage units in other countries. We thus explicitly break with the still dominant view of CHQ as a single unit located at one specific location, and build on the emerging body of research on distributed HQ functions in MNEs. Our rich longitudinal case study within Unilever enabled us to not only gain detailed insights into one of the world's largest manufacturing companies, but also to uncover and theorise some general principles that are 'portable' - what Gioia et al. (2013, p.24) call transferable generalities - concerning the delegation of headquarter-like functions to operating subsidiaries in MNEs.

Central to our findings was the heightened mandate ambiguity as Unilever CHQ pursued its integration strategy. In turn, this ambiguity intensified ongoing cycles of sensemaking and sensegiving about the scope and governance of the RMM, involving multiple subsidiaries and CHQ. While ambiguity may remain largely latent, its manifestation can reveal conflicting or alternative interpretations. Changes in the organisational context of a mandate can lead to ambiguity becoming manifest. This is palpably illustrated in our study of Unilever as a large, complex, historically federative MNE with a tradition of local responsiveness and subsidiary autonomy (see Andersson et al., 2007; Bartlett and Ghoshal, 1989). Mandate ambiguity was present from the time Unilever Hungary was first assigned management responsibility for the SCE region in 1997. However, with minimal overlap between operations in Hungary and the other countries, each organisational unit was more able to interpret the RMM using their own existing interpretive schemes or scripted knowledge. As our findings show, it was only following Unilever Hungary’s efforts towards the integration of Unilever Croatia and Unilever Slovenia from 1999 that the inherent mandate ambiguity began to manifest overtly. From that point, members' heterogeneous 
interpretations concerning the nature of the responsibility contained in the mandate (primary versus secondary) and the existing or expected orientation of members in the mandated subsidiary (control versus support) collided in various ways.

The importance of the concept of mandate ambiguity for explaining the interpretation, implementation and evolution of RMMs was an unanticipated but pivotal finding of our data analysis. To date, the presence of ambiguity in the dispersion and disaggregation of HQ activities has received scant attention. Nell and colleagues’ (2011) found that a clear specialisation in decision-making between corporate HQs, RHQs and subsidiaries is often not achieved, leading to substantial ambiguity of roles, with poor consequences for employee motivation and satisfaction. Yet, the manifestation and consequences of mandate ambiguity for RHQ roles and RMMs have remained unexplored. Similarly, within the broader subsidiary mandate literature, we find only passing mention of mandate ambiguity. For example, Birkinshaw briefly observes that in many cases 'the mandate is fully understood only by the subsidiary that holds it' (1996, p.480) and that the mandate of a new venture division within an MNE is 'fundamentally broader and more ambiguous than that of a research and development group' (1997, p.209). Rugman and Verbeke (2001, p.237) explicitly question prevailing assumptions that subsidiaries can 'somehow be assigned an unambiguous and well defined [mandate].' However, despite acknowledging the existence of mandate ambiguity, its nature and importance has remained underdeveloped.

Outside of the literatures on dispersed HQ activities and subsidiary mandates, ambiguity has been subject to diverse conceptualisations. Some scholars regard it as a strategic tool deliberately employed by leaders to preserve strategic flexibility (Gioia et al., 2012) or to serve certain agendas (Sillince et al., 2012). Others see it as an inherent and irreducible (although to some extent manageable) feature of organisational life (Alvesson, 2001; Alvesson and Sveningsson, 2011; Martin and Meyerson, 1988). McCabe (2010, p.155) 
describes ambiguity as 'an inevitable feature of strategic change that managers can neither evade nor control'. Our findings resonate with this latter view. Of course, the possibility that Unilever’s CHQ might also deliberately use ambiguity as a strategic tool cannot be discounted. Since ambiguity confers flexibility (Gioia et al., 2012), assigning RMMs in such a loosely defined form may offer responsiveness and information processing benefits for the MNE (Alfoldi et al., 2012). This is not, however, incommensurate with our view of ambiguity as an inherent aspect of RMMs. We thus suggest that the importance of ambiguity is not unique to our specific case, RMMs or other forms of distributed HQ functions, but is likely to exist in most subsidiary mandates to varying degrees, whether they are product-oriented or administrative in nature.

Proposition 1: Regional management mandates are inherently ambiguous. The greater the pressures for integration between disparate entities (e.g. subsidiaries, functional areas, work levels) within the MNE, the more manifest is ambiguity for organisational members.

Our study shows that mandate ambiguity - especially in the context of organisational and national differences between MNE units - can create situations that threaten managers' sense of ontological security (including conceptions of identity). These threats, in turn, trigger sensemaking and sensegiving efforts to manage or reduce the perceived threats and 'restore order’ (Giddens, 1991; Maitlis and Christianson, 2014; see also Sandberg and Tsoukas, 2015). An example of such acute (episodic) triggers was the award of the RMM to Hungary, followed by its drastic reduction in scope two years later. Our findings also revealed chronic (ongoing) triggers for sensemaking and sensegiving, such as Unilever's continuing strategic shift towards integration and customer focus. Organisational members engage in ongoing sensemaking in day-to-day activities as they detect different views (e.g. in trainings or clusterlevel meetings) on how to carry out what may seem a fairly routine activity. That is, 
sensemaking is 'ubiquitous rather than exceptional' (Sandberg and Tsoukas, 2015, p.S22), although its intensity may vary at different times and locales.

Proposition 2a: High levels of manifest ambiguity - especially when coupled with increasing levels of integration - create threats to organisational members' ontological security.

Our analysis also highlights how ambiguity and its consequences manifest differently across subsidiaries and at the sub-unit level, varying with managers’ work levels and functional departments. We found differing interpretations about not only the nature of the mandate (primary or secondary responsibility), but also its expected orientation (control or support). Further, our analysis reveals the importance of power and influence (exerted through authoritative/allocative resources and norms of justification) as managers engage in joint sensemaking and sensegiving. As our study shows, RMM-related sensemaking and sensegiving takes place at multiple levels from CHQ to satellite units, down to the sub-unit level. It inevitably involves pushing downwards (e.g. sanctions and enforcement by CHQ and/or the mandated unit) as well as pushing upwards (e.g. resistance and lobbying by the mandated unit and/or satellite units (see also Schotter and Beamish, 2011).

In particular, we found that functional and country managers (WL3) encountered heightened ambiguity. This arose in part because of their role as boundary spanners connecting distinct units within the MNE - and in part because of their position as 'middle management'. Whereas delegating HQ functions to operating subsidiaries may appear to solve coordination problems from the perspective of CHQ, it may merely shift these problems to a location so far removed from the central locus of MNE decision-making that they become virtually invisible to CHQ (Alfoldi et al., 2012). This is consistent with the most senior management in the mandated subsidiary (WL4 and WL5) perceiving little ambiguity in the RMM. For the middle managers (WL3) in the mandated unit or managed subsidiaries, however, there is no such escape. Indeed, we found that the dual roles of a 'local operating 
subsidiary’ and 'RMM authority’ did not go unchallenged by peer subsidiaries, who questioned the legitimacy of the assigned RMM. As Harding and colleagues observe (2014, p.1231), the middle manager responsible for enacting the RMM is 'at once controller, controlled, resister and resisted' - a view that also ties in with Giddens' concept of the dialectic of control, i.e. the two-way character of power in superior-subordinate relationships (see Giddens, 1984, p.374). Experiencing this dialectic of control from multiple directions and across unit boundaries can challenge conceptions of one's identity and 'place in the world', thereby triggering and intensifying efforts at sensemaking and sensegiving for the middle manager.

Proposition 2b: Threats to ontological security are most acutely felt by boundaryspanning middle managers, whose sensemaking and sensegiving efforts are therefore the most intense.

We argue that the ongoing sensemaking and sensegiving efforts displayed in our findings lead to subsidiaries and CHQ jointly co-constructing the RMM over time. This coconstruction process does not merely involve ‘filling gaps’ by simply (re)interpreting unspecified expectations regarding the headquarter-like roles, functions and tasks that a mandated subsidiary is 'supposed' to perform. Instead, it requires units to actively co-create and sanction the specific scope, content and meaning of the mandate and shape it over time in various ways. Notably, this is not an unconstrained creation of RMM scope, content and meaning. As noted earlier, sensemaking and sensegiving processes are informed by underlying social structures (i.e. of signification, legitimation and domination) that persist over time and space (Giddens, 1979). These structures are instantiated (or become 'real') only when reflexive and knowledgeable agents communicate meanings, deploy power, and invoke norms and sanctions through their actions. Hence, we see regional management mandates as instantiations of abstract social structures (see also Jarzabkowski, 2008). 
To the extent that institutionalised social structures guide sensemaking and sensegiving, members of the MNE produce and reproduce these organisation-wide and locally embedded social structures through enacting and co-constructing the RMM. Nevertheless, the relationship is not deterministic: members of CHQ and subsidiaries remain (boundedly) knowledgeable and reflexive agents who have the capacity to choose how they act. In doing so, they may either sustain or modify the institutionalised meanings, normative elements or power structures within the MNE (Giddens, 1979, 1984, 1991). We thus see mandate coconstruction as a process of structuration - a recursive process whereby structural elements (i.e. interpretive schemes, norms of justification and allocative/authoritative resources) enable and constrain agency (i.e. sensemaking and sensegiving). In turn, agency produces, reproduces and modifies these structural elements. Our arguments are formalised in our final proposition:

Proposition 3: Cycles of joint sensemaking and sensegiving lead to the (multilateral) coconstruction of the regional management mandate by organisational members of affected subsidiaries and CHQ, through a constantly evolving process of structuration.

\section{CONCLUSIONS}

While the context of the MNE provides unique opportunities for the development of new theorisations of organisational phenomena, this potential remains under-utilised. More broadly, the field of international business has been criticised for failing to make its insights relevant across disciplines (Liesch et al., 2011; Sullivan et al., 2011). Our study responds to both of these laments. We show that complex MNE structures with distributed HQ configurations present a fertile ground for novel insights and theory building. As such, our contributions extend beyond international business to the broader management and organisation literatures. 
Our findings and conceptual framework bring ambiguity centre stage and make explicit a baseline assumption that has hitherto been only hinted at in the literatures on distributed HQ activities and subsidiary mandates: RMMs are inherently ambiguous, although this ambiguity may not always manifest. While ambiguity may allow a level of strategic flexibility and local responsiveness, it can also lead to unintended consequences (Giddens, 1984; Lawrence et al., 2009; McGaughey, 2013) as MNE units co-construct the RMM in unexpected ways. For example, ambiguity may allow subsidiary managers to interpret the RMM using their existing scripted knowledge, so that they may retain their preferred behaviours and preserve ontological security - even when this is not desirable from the perspective of CHQ or other subsidiaries. At other times, ambiguous and conflicting interpretations of the nature and orientation of the mandate may create threats to organisational members' ontological security. The resultant sensemaking and sensegiving in mandate co-construction may also help explain the regular restructurings and reorganisations within regions that are widely observed in MNEs (Alfoldi et al., 2012; Chakravarty et al., 2017; Nell et al., 2011; Piekkari et al., 2010). Our study highlights the importance of better understanding the manifestation, consequences and multiple responses to ambiguity in MNEs.

We also offer a new baseline assumption about how RMMs are interpreted and put into practice: RMMs are co-constructed through processes of sensemaking and sensegiving involving multiple involved parties. At the outset of our study, this assumption was nonobvious. Whereas RMMs - and subsidiary mandates more generally - are typically depicted as either unilaterally assigned by CHQ or negotiated between CHQ and the mandated subsidiary, our empirical study shows otherwise. Notably, when we compared what is depicted in the extant literature with possible interpretations of our data, we found a 'radical distinction between seeming and being' - or between '[RMM] phenomenology' and '[RMM] ontology’ (Davis, 1971, p.313). In other words, even though RMMs may seem to be 
assigned/initiated unilaterally or negotiated in a dyadic fashion, our study shows them as being characterised by co-construction involving multiple subsidiaries and CHQ. This theorisation is, of course, consistent with longstanding notions of the MNE as a heterarchy (Hedlund, 1986) or a differentiated network (e.g. Nohria and Ghoshal, 1994).

Why, then, do we so often find simplified assumptions of unilateral or dyadic accomplishments in the literatures on distributed HQ activities and subsidiary mandates? One possibility is a perceived disciplinary preference for testable hypotheses to accumulate useful knowledge (Cornelissen, 2017; Harris et al., 2013). This removes layers of complexity in the 'lived experience.' Another possibility is that over time, assumptions become 'formless' and 'floating' (Davis, 1971). Such assumptions may only become apparent when we attempt to better identify and conceptualise a novel phenomenon’s salient aspects. Regardless of any such speculation, we expect that this new baseline assumption will apply to many forms of mandate assignment within MNEs.

Our conceptual framework and propositions are not intended to specify a testable set of relationships between variables. Rather, by identifying relationships between constructs and challenging longstanding assumptions, they serve as guideposts for further research (Cornelissen, 2017). Knowledge of distributed HQ functions - and subsidiary mandates more broadly - accumulates as studies develop new representations (models, frameworks, narratives etc.) that more closely match the lived experience of organisational members at various levels. Application of our sensemaking-sensegiving framework depicting the coconstruction of RMMs may, for example, help illuminate recent findings on the evolution of regional structures - including shifts from the use of RMMs to RHQs, from RHQs to RMMs, and the changing usage of dual models (see Chakravarty et al., 2017).

Our integration of concepts from structuration theory with sensemaking and sensegiving perspectives makes a contribution beyond international management. As Maitlis 
and Christianson (2014, p.99) observe in their extensive review of sensemaking and sensegiving: 'Quite overlooked, or certainly underplayed, are the social, cultural, economic, and political forces that shape what groups will notice, how they can act, with whom they interact, and the kinds of environments that can be collectively enacted...[and the] opportunity to advance our understanding of power and sensemaking is still considerable.' Our theorising directly responds to this observation by integrating elements of social structure proposed by Giddens (1979) into to our perspective on sensemaking and sensegiving. These elements include interpretive schemes (i.e. structures of signification); allocative and authoritative resources (i.e. structures of domination); and norms of justification (i.e. structures of legitimation). According to Giddens (1979), all social practices inevitably involve structures of signification, domination and legitimation, yet - to the best of our knowledge - we are the first to explicitly integrate them into a conceptualisation of sensemaking and sensegiving. As researchers increasingly seek to accumulate knowledge grouped by phenomena rather than by perceived disciplinary boundaries, borrowing and integrating across traditions is likely to become more pronounced (Harris et al., 2013). Hence, we hope that scholars from across traditions will build on, refine and extend our theorisation around the co-construction of RMMs, and further explore the potential contribution of structuration theory to sensemaking and sensegiving perspectives in management and organisation studies.

\section{Acknowledgements}

We sincerely thank the Society for the Advancement of Management Studies (SAMS) for their generous funding; all our respondents who shared their valuable insights; and the Special Issue and General editors, four anonymous reviewers, and co-participants at the paper development workshop in Vienna for their guidance and detailed suggestions. 


\section{References}

Albert, S. and Whetten, D. A. (1985). Organizational identity. Research in Organizational Behavior, 7, 263-295.

Alfoldi, E. A., Clegg, L. J. and McGaughey, S. L. (2012). Coordination at the Edge of the Empire: The Delegation of Headquarters Functions through Regional Management Mandates. Journal of International Management, 18, 276-292.

Alvesson, M. (2001). Knowledge work: Ambiguity, image and identity. Human Relations, 54, 863-886.

Alvesson, M. and Sandberg, J. (2013). Has Management Studies Lost Its Way? Ideas for More Imaginative and Innovative Research. Journal of Management Studies, 50, 128152.

Alvesson, M. and Sveningsson, S. (2011). Management is the solution: Now what was the problem? On the fragile basis for managerialism. Scandinavian Journal of Management, 27, 349-361.

Ambos, T., Schlegelmilch, B., Ambos, B. and Brenner, B. (2009). Evolution of Organisational Structure and Capabilities in Internationalising Banks: The CEE Operations of UniCredit's Vienna Office. Long Range Planning, 42, 633.

Andersson, U., Forsgren, M. and Holm, U. (2007). Balancing subsidiary influence in the federative MNC: a business network view. Journal of International Business Studies, 38, 802.

Ashforth, B. E., Harrison, S. H. and Corley, K. G. (2008). Identification in Organizations: An Examination of Four Fundamental Questions. Journal of Management, 34, 325.

Baaij, M. G., Mom, T. J. M., Van den Bosch, F. A. J. and Volberda, H. W. (2015). Why Do Multinational Corporations Relocate Core Parts of Their Corporate Headquarters Abroad? Long Range Planning, 48, 46-58.

Baaij, M. G. and Slangen, A. H. L. (2013). The role of headquarters-subsidiary geographic distance in strategic decisions by spatially disaggregated headquarters. Journal of International Business Studies, 44, 941-952.

Bartlett, C. A. and Ghoshal, S. (1989). Managing Across Borders: The Transnational Solution. Boston: Harvard Business School Press.

Bartunek, J. M. (1984). Changing interpretive schemes and organization restructuring: the example of a religious order. Administrative Science Quarterly, 29, 335-372.

Birkinshaw, J. (1996). How multinational subsidiary mandates are gained and lost. Journal of International Business Studies, 27, 467.

Birkinshaw, J. (1997). Entrepreneurship in multinational corporations: The characteristics of subsidiary initiatives. Strategic Management Journal, 18, 207.

Birkinshaw, J., Braunerhjelm, P., Holm, U. and Terjesen, S. (2006). Why do some multinational corporations relocate their headquarters overseas? Strategic Management Journal, 27, 681.

Birkinshaw, J. and Hood, N. (1998). Multinational subsidiary evolution: Capability and charter change in foreign-owned subsidiary companies. Academy of Management Review, 23, 773.

Brown, A. D., Colville, I. and Pye, A. (2015). Making Sense of Sensemaking in Organization Studies. Organization Studies, 36, 265.

Chakravarty, D., Hsieh, Y.-Y., Schotter, A. P. J. and Beamish, P. W. (2017). Multinational enterprise regional management centres: Characteristics and performance. Journal of World Business, 52, 296-311. 
Ciabuschi, F., Dellestrand, H. and Holm, U. (2012). The role of headquarters in the contemporary MNC. Journal of International Management, 18, 213-223.

Conroy, K. M. and Collings, D. G. (2016). The Legitimacy of Subsidiary Issue Selling: Balancing Positive and Negative Attention from Corporate Headquarters. Journal of World Business, 51, 612-627.

Cornelissen, J. P. (2017). Developing Propositions, a Process Model, or a Typology? Addressing the Challenges of Writing Theory Without a Boilerplate. Academy of Management Review, 42, 1-9.

Davis, M. S. (1971). That's interesting: Towards a phenomenology of sociology and a sociology of phenomenology. Philosophy of the Social Sciences, 1, 309-344.

Denzin, N. and Lincoln, Y. (Eds.). (2000). Handbook of Qualitative Research (2nd ed.). Thousand Oaks: Sage.

Dew, N. (2007). Abduction: a pre-condition for the intelligent design of strategy. Journal of Business Strategy, 28, 38-45.

Dörrenbächer, C. and Gammelgaard, J. (2006). Subsidiary role development: The effect of micro-political headquarters-subsidiary negotiations on the product, market and valueadded scope of foreign-owned subsidiaries. Journal of International Management, 12, 266-283.

Dörrenbächer, C. and Gammelgaard, J. (2016). Subsidiary Initiative Taking in Multinational Corporations: The Relationship between Power and Issue Selling. Organization Studies, 37, 1249-1270.

Dutta, D. K., Malhotra, S. and Zhu, P. (2016). Internationalization Process, Impact of Slack Resources, and Role of the CEO: The Duality of Structure and Agency in Evolution of Cross-Border Acquisition Decisions. Journal of World Business, 51, 212-225.

Dutton, J. E. and Dukerich, J. M. (1991). Keeping an Eye on the Mirror: Image and Identity in Organizational Adaptation. Academy of Management Journal, 34, 517.

Egelhoff, W. G. (2010). How the Parent Headquarters Adds Value to an MNC. Management International Review, 50, 413.

Foss, K., Foss, N. J. and Nell, P. C. (2012). MNC organizational form and subsidiary motivation problems: controlling intervention hazards in the network MNC. Journal of International Management, 18, 247-259.

Galunic, D. C. and Eisenhardt, K. M. (1996). The evolution of intracorporate domains: Divisional charter losses in high-technology, multidivisional corporations. Organization Science, 7, 255.

Geppert, M., Becker-Ritterspach, F. and Mudambi, R. (2016). Politics and Power in Multinational Companies: Integrating the International Business and Organization Studies Perspectives. Organization Studies, 37, 1209-1225.

Giddens, A. (1979). Central problems in Social Theory: Action, Structure and Contradiction in Social Analysis. London: Macmillan.

Giddens, A. (1984). The Constitution of Society. Outline of the Theory of Structuration. Cambridge: Polity.

Giddens, A. (1991). Modernity and Self-Identity: Self and Society in the Late Modern Age. Cambridge: Polity.

Gioia, D. A. and Chittipeddi, K. (1991). Sensemaking and Sensegiving in Strategic Change Initiation. Strategic Management Journal, 12, 433-433.

Gioia, D. A., Corley, K. G. and Hamilton, A. L. (2013). Seeking Qualitative Rigor in Inductive Research: Notes on the Gioia Methodology. Organizational Research Methods, 16, 15-31. 
Gioia, D. A., Nag, R. and Corley, K. G. (2012). Visionary Ambiguity and Strategic Change: The Virtue of Vagueness in Launching Major Organizational Change. Journal of Management Inquiry, 21, 364.

Goold, M. and Campbell, A. (2002). Parenting in complex structures. Long Range Planning, 35, 219-243.

Gupta, A. K. and Govindarajan, V. (1991). Knowledge Flows and the Structure of Control Within Multinational Corporations. Academy of Management Review, 16, 768.

Harding, N., Lee, H. and Ford, J. (2014). Who is 'the middle manager'? Human Relations, 67, 1213-1237.

Harris, J. D., Johnson, S. G. and Souder, D. (2013). Model-Theoretic Knowledge Accumulation: The Case of Agency Theory and Incentive Alignment. Academy of Management Review, 38, 442-454.

Hedlund, G. (1986). The Hypermodern MNC -- A Heterarchy? Human Resource Management, 25, 9.

Jarzabkowski, P. (2008). Shaping strategy as a structuration process. Academy of Management Journal, 51, 621.

Lasserre, P. (1996). Regional headquarters: The spearhead for Asia Pacific markets. Long Range Planning, 29, 30.

Lawrence, T. B., Suddaby, R. and Leca, B. (2009). Institutional Work: Actors and Agency in Institutional Studies of Organization. Cambridge: Cambridge University Press.

Li, G.-H., Yu, C.-M. and Seetoo, D.-H. (2010). Toward a Theory of Regional Organization: The Emerging Role of Sub-regional Headquarters and the Impact on Subsidiaries. Management International Review, 50, 5.

Liesch, P. W., Hakanson, L., McGaughey, S. L., Middleton, S. and Cretchley, J. (2011). The evolution of the international business field: a scientometric investigation of articles published in its premier journal. Scientometrics, 88, 17-42.

Maitlis, S. and Christianson, M. (2014). Sensemaking in Organizations: Taking Stock and Moving Forward. Academy of Management Annals, 8, 57-125.

Martin, J. and Meyerson, D. (1988). 'Organizational cultures and the denial, channeling and acknowledgement of ambiguity'. In L. R. Pondy (Ed.), Managing Ambiguity and Change. New York: Wiley.

McCabe, D. (2010). Strategy-as-Power: Ambiguity, Contradiction and the Exercise of Power in a UK Building Society. Organization, 17, 151-175.

McGaughey, S. L. (2013). Institutional entrepreneurship in North American lightning protection standards: Rhetorical history and unintended consequences of failure. Business History, 55, 73-97.

Menz, M., Kunisch, S. and Collis, D. J. (2015). The Corporate Headquarters in the Contemporary Corporation: Advancing a Multimarket Firm Perspective. Academy of Management Annals, 9, 633-714.

Mills, J. H., Thurlow, A. and Mills, A. J. (2010). Making sense of sensemaking: the critical sensemaking approach. Qualitative Research in Organizations and Management, 5, 182.

Nell, P. C., Ambos, B. and Schlegelmilch, B. B. (2011). 'The benefits of hierarchy? Exploring the effects of regional headquarters in multinational corporations'. In C. G. Asmussen, T. Pedersen, T. Devinney M. \& L. Tihanyi (Eds.), Advances in International Management, Vol. 24: Dynamics of Globalization: Location-Specific Advantages or Liabilities of Foreignness? Bingley: Emerald, Vol. 24, 85-106.

Nell, P. C. and Ambos, B. r. (2013). Parenting advantage in the MNC: An embeddedness perspective on the value added by headquarters. Strategic Management Journal, 34, 1086. 
Nohria, N. and Ghoshal, S. (1994). Differentiated fit and shared values: Alternatives for managing headquarters-subsidiary relations. Strategic Management Journal, 15, 491.

Peirce, C. S. (1960). Collected papers of Charles Sanders Peirce. Cambridge: Harvard University Press.

Piekkari, R., Nell, P. and Ghauri, P. (2010). Regional Management as a System: A Longitudinal Case Study. Management International Review, 50, 513.

Preece, D., Iles, P. and Jones, R. (2013). MNE regional head offices and their affiliates: talent management practices and challenges in the Asia Pacific. The International Journal of Human Resource Management, 24, 3457.

Rugman, A. M. and Verbeke, A. (2001). Subsidiary-specific advantages in multinational enterprises. Strategic Management Journal, 22, 237.

Rugman, A. M., Verbeke, A. and Yuan, W. (2011). Re-conceptualizing Bartlett and Ghoshal's Classification of National Subsidiary Roles in the Multinational Enterprise. Journal of Management Studies, 48, 253-277.

Ryle, G. (1968). Collected Essays 1929 - 1968. London: Hutchinson.

Sandberg, J. and Tsoukas, H. (2015). Making sense of the sensemaking perspective: Its constituents, limitations, and opportunities for further development. Journal of Organizational Behavior, 36, S6-S32.

Schotter, A. and Beamish, P. W. (2011). Performance effects of MNC headquarterssubsidiary conflict and the role of boundary spanners: the case of headquarter initiative rejection. Journal of International Management, 17, 243-259.

Schotter, A., Stallkamp, M. and Pinkham, B. C. (this issue). MNE Headquarters Disaggregation: The Formation Antecedents of Regional Management Centers. Journal of Management Studies.

Schütte, H. (1997). Strategy and organisation: Challenges for European MNCs in Asia. European Management Journal, 15, 436.

Schuh, A. (2013). Central and Eastern Europe After the Boom - Time for a Strategy Change for Foreign Multinationals? Central European Business Review, 2, 25-30.

Sillince, J., Jarzabkowski, P. and Shaw, D. (2012). Shaping Strategic Action Through the Rhetorical Construction and Exploitation of Ambiguity. Organization Science, 23, 630-650.

Stake, R. E. (1995). The Art of Case Study Research. Thousand Oaks: Sage Publications.

Sullivan, D., Nerur, S. P. and Balijepally, V. (2011). Source or storer? IB's performance in a knowledge network. Journal of International Business Studies, 42, 446-457.

Tempel, A. and Walgenbach, P. (2007). Global Standardization of Organizational Forms and Management Practices? What New Institutionalism and the Business-Systems Approach Can Learn from Each Other. Journal of Management Studies, 44, 1.

Thomas, J. B., Clark, S. M. and Gioia, D. A. (1993). Strategic sensemaking and organizational performance: Linkages among scanning, interpretation, action, and outcomes. Academy of Management Journal, 36, 239.

Unilever. (2016). Annual Report. Available at: https://www.unilever.com/investorrelations/annual-report-and-accounts/\#ara2016-downloads.

Van Maanen, J. C. F. p. d. D. (1979). The Fact of Fiction in Organizational Ethnography. Administrative Science Quarterly, 24, 539-550.

Weick, K. E. (1995). Sensemaking in Organizations. Thousand Oaks: Sage.

Weick, K. E., Sutcliffe, K. M. and Obstfeld, D. (2005). Organizing and the process of sensemaking. Organization Science, 16, 409-421.

Wolcott, H. F. (1999). Ethnography: A Way of Seeing. Oxford: AltaMira.

Yin, R. K. (2013). Case Study Research: Design and Methods. (5) 5th edition. Thousand Oaks, CA.: Sage Publications. 


\section{Tables and Figures}

Table I. Unilever interviews, 2005-2007

\begin{tabular}{|c|c|c|c|c|c|c|}
\hline Subsidiary unit & $\begin{array}{l}\text { Number of } \\
\text { respondents }\end{array}$ & $\begin{array}{l}\text { Interview } \\
\text { language }\end{array}$ & $\begin{array}{l}\text { Employee } \\
\text { status }^{1}\end{array}$ & $\begin{array}{l}\text { Functional } \\
\text { department }^{2}\end{array}$ & $\begin{array}{l}\text { Work } \\
\text { level }^{3}\end{array}$ & Gender \\
\hline $\begin{array}{l}\text { Unilever Hungary } \\
\text { Size: } 400+\text { employees (plus around } \\
500 \text { workers at the } 3 \text { factories in } \\
\text { Nyírbátor, Veszprém and Röszke) }\end{array}$ & 18 & 18 Hungarian & $\begin{array}{l}12 \text { Current } \\
6 \text { Former }\end{array}$ & $\begin{array}{l}5 \text { General } \\
6 \text { Trade marketing } \\
3 \text { Marketing } \\
2 \text { HR } \\
2 \text { Factory } \\
\end{array}$ & $\begin{array}{l}5 \mathrm{WL} 4 \\
7 \mathrm{WL3} \\
3 \mathrm{WL2} \\
3 \mathrm{WL1}\end{array}$ & $\begin{array}{l}10 \text { Female } \\
8 \text { Male }\end{array}$ \\
\hline $\begin{array}{l}\text { Unilever Croatia } \\
\text { Size: } 65 \text { employees (no factory) }\end{array}$ & 5 & 5 English & $\begin{array}{l}4 \text { Current } \\
1 \text { Former }\end{array}$ & $\begin{array}{l}\text { General } \\
3 \text { Trade marketing } \\
1 \text { Marketing }\end{array}$ & $\begin{array}{l}1 \mathrm{WL3} \\
2 \mathrm{WL2} \\
2 \mathrm{WL1} \\
\end{array}$ & $\begin{array}{l}3 \text { Female } \\
2 \text { Male }\end{array}$ \\
\hline $\begin{array}{l}\text { Unilever Slovenia } \\
\text { Size: } 27 \text { employees (no factory) }\end{array}$ & 5 & 5 English & $\begin{array}{l}4 \text { Current } \\
1 \text { Former }\end{array}$ & $\begin{array}{l}1 \text { General } \\
3 \text { Trade marketing } \\
1 \text { Marketing }\end{array}$ & $\begin{array}{l}1 \mathrm{WL} 3 \\
4 \mathrm{WL1}\end{array}$ & 5 Female \\
\hline $\begin{array}{l}\text { CEE regional board at CHQ } \\
\text { Size: } 5-25 \text { employees (has varied in } \\
\text { size and function over time) }\end{array}$ & 2 & 5 English & 2 Current & 2 General & 2 WL5 & 2 Male \\
\hline Total & 30 & 30 & 30 & 30 & 30 & 30 \\
\hline
\end{tabular}

${ }^{1}$ Current denotes the time of data collection. Two former employees still worked with UL as external consultants.

${ }^{2}$ Main or most recent position (many respondents moved frequently). Some also moved between units at times.

${ }^{3}$ Due to the size and structural complexity of Unilever, the definition of work levels is complicated and contains overlaps. As a rough guide: $\mathbf{W L 6}=$ global executive board, inc. directors of business lines and 'triad' regions; WL5 = regional or cluster-level chair(wo)men; WL4 = cluster-level directors; $\mathbf{W L} 3$ = functional department or country unit managers (middle managers); WL2/WL1 = operating and assistant managers 'on the ground'. 


\section{Figure 1. Data structure using inductive principles}

\section{First-order themes}

Interpretations of RMM vary by work level and functional department (marketing/trade marketing)

RMM perceived either as geographical extension of existing responsibilities or the addition of new ones

Purpose of RMM perceived either as monitoring and enforcement; or help and knowledge transfer - some managers experience conflicts between the two

Drive towards integration; evolution of customer focus; outsourcing; internal restructuring; changing personnel; moving between positions and job roles

Geographical \& hierarchical distance between units

Local, regional or global connectedness within UL

Unit size; history; perceived success; competences; national identity and culture; relative levels of market development and perceived consumer sophistication

Changes in RMM scope; external jolts; failed product launches (acute); strategic shifts; conflicts (chronic)

Empirical knowledge (own experience); institutional knowledge (how things are done in UL); reasons for RMM allocation, collaboration and use of resources

Identities; emotions; information access; filtering;

bias; unacknowledged conditions; erroneous beliefs

Influence through superior financial budgets, infrastructures and systems - or lack thereof

nfluence through assigned authority; hierarchical or social position; information access; recognised expertise; autonomy; market development level

Fulfil CHQ expectations; minimise risks; spread best practices; need for trust and tact in communication

\section{Second-order concepts}

State concepts

\section{Process concepts}
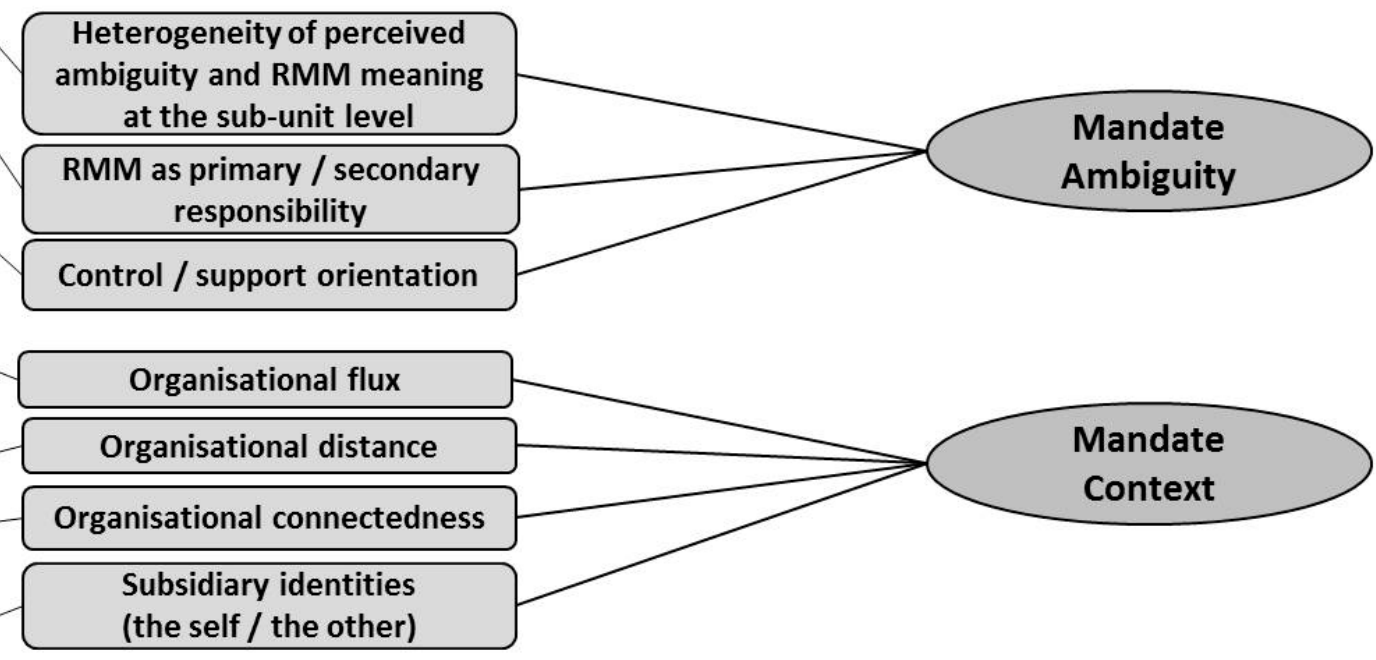

\section{Threats to identity and threats to ontological security as sensemaking triggers \\ Interpretive schemes and norms of justification \\ Bounded knowledgeability}

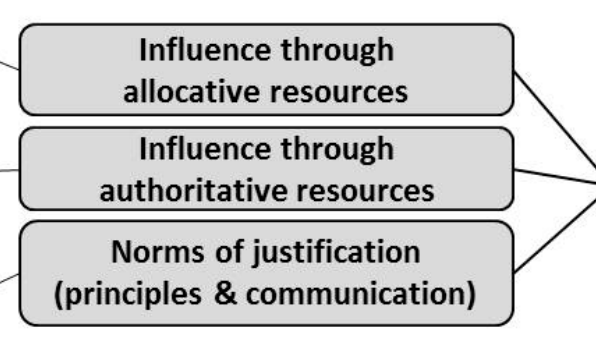

Sensegiving

about the

mandate 
Figure 2. Unilever's regional organisational structure in 2006

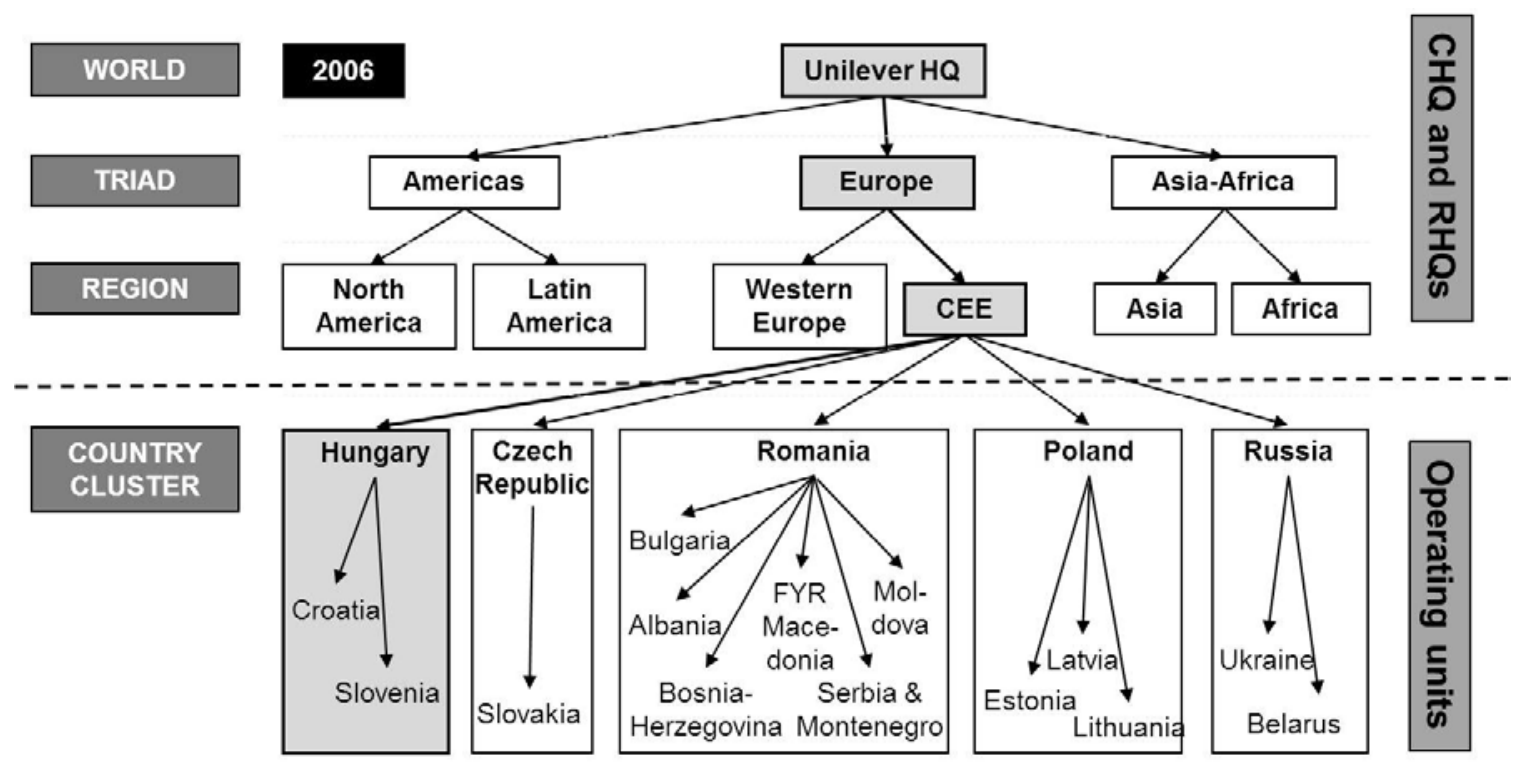

Source: Interview data, Unilever annual report (2006)

\section{Figure 3. Conceptual framework}

\section{Mandate Context}

Federated MNE with a view to integration

- Organisational flux (integration drive)

- Organisational distance and connectedness between units/within the MNE

- Subsidiary identities (self versus the other)

\section{Mandate Ambiguity} Inherent in regional management mandates

- Heterogeneity in perceived meaning at the subunit level (by work level \& functional department)

- Primary versus secondary responsibility

- Control versus support orientation
Acute and chronic threats to identity / to ontological security

\section{Sensemaking}

- Use of interpretive schemes (empirical \& institutional)

- Norms of justification to self

- Affected by the bounded knowledgeability of agents

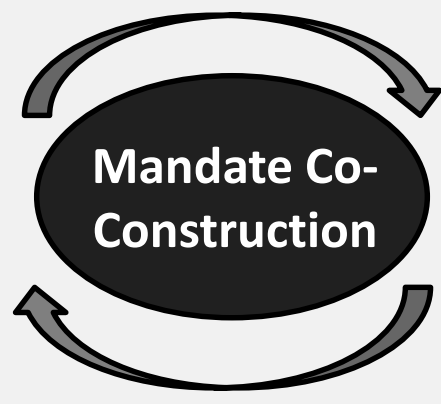

- Ongoing changes in the scope \& governance of the regional management mandate over time

\section{Sensegiving}

- Power \& influence via allocative resources (command over objects)

- Power \& influence via authoritative resources (command over people)

- Norms of justification to others (principles as well as communication strategies) 
Figure 4. Timeline of events and changes at various levels within Unilever (1990-2007)

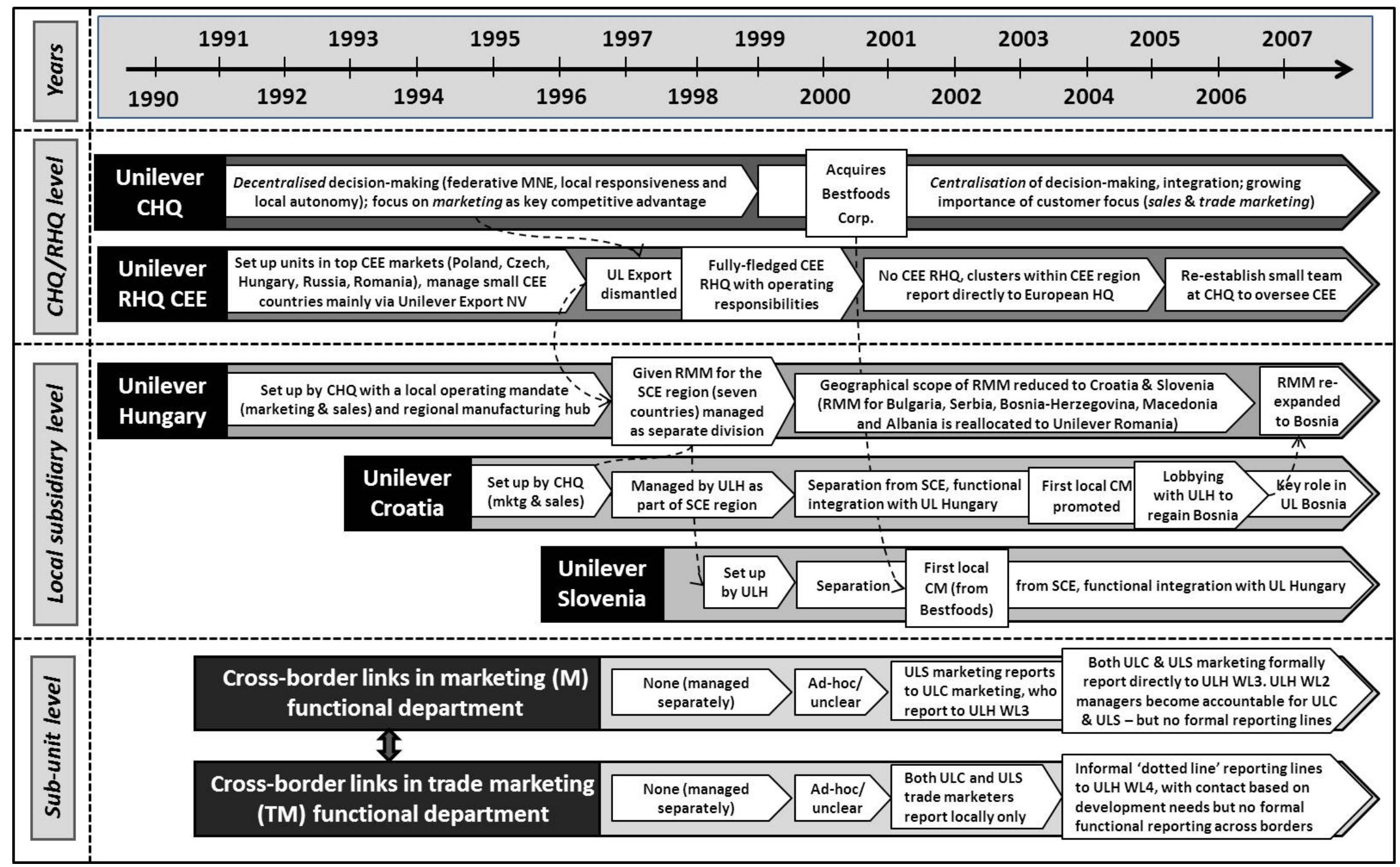

Source: Interview data 


\section{Mandate ambiguity}

\section{Heterogeneity in perceived mandate ambiguity and mandate interpretations}

by work level and functional department

'In my view, there is no ambiguity whatsoever.' (Former ULH chairman, CEE regional director, WL5)

'They belonged to us in a roundabout way...the situation was a little uneven, because even Unilever could not define exactly how these two countries were connected to us.' (Hungarian manager, WL3)

'They didn't know what they had to do about us: is it just information sharing, or is there also some leading responsibility?' (Slovenian manager) Mandate as a primary versus secondary responsibility

'I am responsible for all countries. I am physically sitting in Hungary but in fact I represent all three countries. So whatever forum I participate in, I have to think in terms of these three countries.' (Hungarian director, WL4)

'Everyone did their own little things [...] if I thought about who my team were, Croatia and Slovenia were not part of it in such an organic way.' (Hungarian trade marketing manager, WL3)

'Whenever we asked the Hungarian team to the present us something or to share something with us, they did it. But they didn't do it independently

[...] We had to initiate it because we are small, and they are so occupied with their everyday and current business that they didn't think about us.' (Slovenian manager)

Mandate oriented towards control versus support

'The financial directors [in ULH] have always kept the Croatian books [...] so there was very serious control there.' (Hungarian manager, WL3) 'It's important for [Croatian and Slovenian colleagues] to fulfil the business expectations that we have regarding promotions.' (Hungarian marketing manager, WL3)

'It was more a supporting role that we tried to provide, not to force them into an organisation they were not part of.' (Hungarian manager, WL3)

'My boss [...] was indirectly responsible for the Croatian and Slovenian businesses, but actually, this only meant that if the colleagues there asked for something or we were trying to help them, then she did so [...] she was just trying to help.’ (Hungarian manager, WL2)
Mandate context (Federative MNE with a view to integration)

\section{Organisational flux (strategic restructuring and personnel fluctuation)}

'If Unilever changes globally, this is guaranteed to affect the clusters and the individual countries in each cluster. So I have to say there is massive change in the background.' (Hungarian director, WL4)

'People on our side were changing regularly [...] this doesn't help this co-operation and connection.' (Slovenian manager)

'People are coming and leaving [...] in a few years, there is a completely new TM department; and we somehow cannot follow.' (Croatian manager) Organisational distance (horizontal and vertical)

'Sometimes, it's difficult because we're managing ourselves over a

distance $[. .$.$] People don't see you every day, so...it is much more$ managing up than managing down, you know? (Croatian manager)

'[Slovenian colleagues] are relatively far from us and it's difficult to take them for trainings.' (Hungarian manager, WL1)

'In Croatia, they are already two levels down from us, because even the country manager is only WL3 [...] A WL3 person has a much smaller lobbying power than a WL5 person.' (Hungarian manager, WL3) Organisational connectednes

'In the Adriatic, it is hard for them to feel part of a global organisation.' (Hungarian director, WL4)

'I have attended several international meetings while as small countries, they are only present at relatively few places.' (Hungarian manager, WL2) '[Our customer] was asking "What's the strategy for TM [...] in Western countries?” And then it was my [problem] who to ask, because I don't have any contacts in Western countries.' (Slovenian manager)

\section{Subsidiary identity (view of the self and of 'the other')}

'Hungary is still much more developed in terms of retail structure than

Croatia or Slovenia.' (Hungarian manager, WL3)

'What might be attractive for Hungarians... does not necessarily mean that it is attractive enough for Croatians.' (Croatian manager)

'We don't consider ourselves as Eastern Europe because we have a lot of influences from Austria and Italy.' (Slovenian manager)

'It's very difficult...to be a Hungarian in a "Slavic sea" and be a leader in these countries.' (Hungarian manager, WL3) 


\begin{tabular}{|c|c|}
\hline Sensemaking & Sensegiving \\
\hline 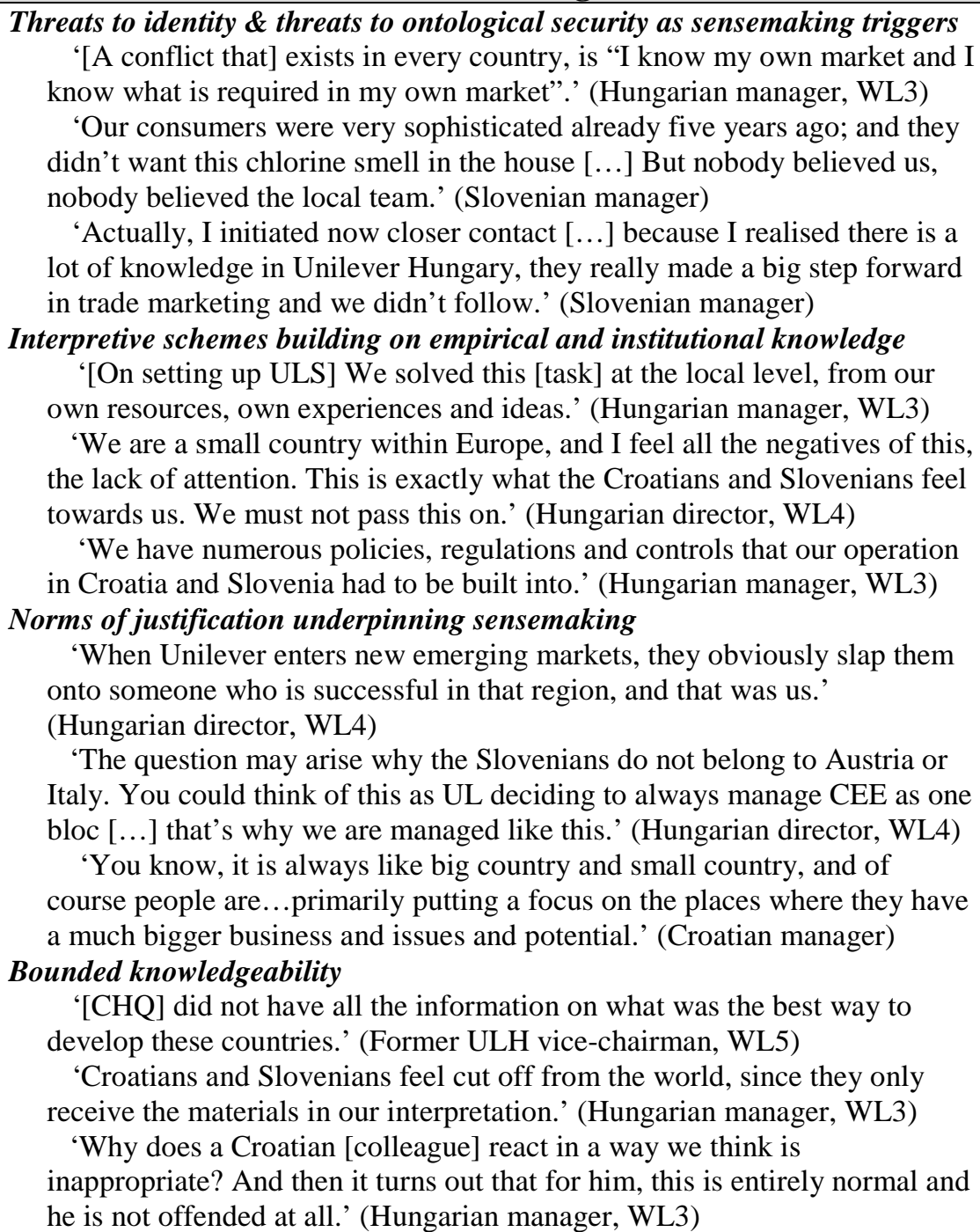 & $\begin{array}{l}\text { (Lack of) influence through mobilising allocative resources } \\
\text { 'I did not see any local innovation in the Slovenian marketing function, } \\
\text { because I think their budget was too small.' (Hungarian manager, WL1) } \\
\text { 'They often feel frustrated and powerless because they understand what } \\
\text { we are talking about, they are willing to implement it, but they do not have } \\
\text { the infrastructure for it.' (Hungarian manager, WL3) } \\
\text { Influence through mobilising authoritative resources } \\
\text { '[Croatian and Slovenian marketing plans are] subject to my approval.' } \\
\text { (Hungarian marketing manager, WL3) } \\
\text { 'Hungary is, I would say, 2-3 years in front of us. But the good thing } \\
\text { from that is that we can learn from that experience.' (Croatian manager) } \\
\text { '[The free gifts attached to Unilever's products in Hungary]...quality- } \\
\text { wise, were not good enough for this market, because the market is more } \\
\text { demanding. So we went our own way there.' (Slovenian manager) } \\
\text { Norms of justification (principles) underpinning sensegiving } \\
\text { 'They receive strategy and targets from me. As I receive this from my } \\
\text { boss, this cascades down beautifully from Europe to CEE, to the clusters } \\
\text { and the individual countries.' (Hungarian director, WL4) } \\
\text { '[The cost allocation system] is one of those necessary things that have } \\
\text { to be done by everyone, as a huge risk is created if this is not working.' } \\
\text { (Hungarian manager, WL3) } \\
\text { '[My expatriation to Slovenia] was a kind of best practice thing, to take } \\
\text { the Hungarian way of working over there.' (Hungarian manager, WL1) } \\
\text { Norms of justification (communication) underpinning sensegiving } \\
\text { 'The Croatians are a bit excluded, you can tell [...] this brings out a } \\
\text { sensitivity in them that I, as their leader, must be especially alert to [...] I } \\
\text { have never written them an email that did not start with “Dear X”. It’s a } \\
\text { small thing but necessary, unlike in Hungary.' (Hungarian director, WL4) } \\
\text { 'We found that it would be a dead end if we said “come on and learn, } \\
\text { dummy”. So we had to organise workshops, joint forums, joint work; we'd } \\
\text { design things together.' (Hungarian manager, WL3) } \\
\text { 'This is the 'lead by example' story, so if I give them directions and show } \\
\text { a behaviour that reflects this to them, this system will work.' (Hungarian } \\
\text { manager, WL3) }\end{array}$ \\
\hline
\end{tabular}


